\title{
GERMS IN THE FAMILY: \\ THE LONG-TERM CONSEQUENCES OF \\ INTRA-HOUSEHOLD ENDEMIC RESPIRATORY DISEASE SPREAD
}

\author{
N. Meltem Daysal \\ Hui Ding \\ Maya Rossin-Slater \\ Hannes Schwandt \\ Working Paper 29524 \\ http://www.nber.org/papers/w29524
}

\section{NATIONAL BUREAU OF ECONOMIC RESEARCH \\ 1050 Massachusetts Avenue \\ Cambridge, MA 02138}

November 2021

We thank Jon Guryan, and conference and seminar participants at the Barcelona Graduate School of Economics Summer Forum, the 2021 American Society of Health Economists annual meeting, the 2021 European Economic Association meeting, the 77th Annual Congress of the International Institute of Public Finance, the Ca'Foscari University of Venice, University of Milan, Universita Cattolica, UC Irvine, and VATT Institute for Economic Research Helsinki for helpful comments. The views expressed herein are those of the authors and do not necessarily reflect the views of the National Bureau of Economic Research.

NBER working papers are circulated for discussion and comment purposes. They have not been peer-reviewed or been subject to the review by the NBER Board of Directors that accompanies official NBER publications.

(C) 2021 by N. Meltem Daysal, Hui Ding, Maya Rossin-Slater, and Hannes Schwandt. All rights reserved. Short sections of text, not to exceed two paragraphs, may be quoted without explicit permission provided that full credit, including $\odot$ notice, is given to the source. 
Germs in the Family: The Long-Term Consequences of Intra-Household Endemic Respiratory

Disease Spread

N. Meltem Daysal, Hui Ding, Maya Rossin-Slater, and Hannes Schwandt

NBER Working Paper No. 29524

November 2021

JEL No. I12,I14,I18,J13

\begin{abstract}
While the COVID-19 pandemic has laid bare the large costs of infectious diseases, less attention has been paid to the impacts of more common, endemic respiratory viruses that frequently circulate in the population, especially when it comes to their potential long-term consequences for population health, human capital, and economic outcomes. This paper uses Danish populationlevel administrative data on 35 birth cohorts of children to provide a comprehensive analysis of both the mechanisms through which infants become infected by respiratory illnesses, as well as the consequences of early-life respiratory disease exposure for their later outcomes. First, we document a striking difference in the likelihood of severe respiratory illness by birth order: younger siblings have two to three times higher rates of hospitalization for respiratory conditions before age one than older siblings at the same age. We argue that the family unit is central in virus transmission, with older children "bringing home" the virus to their younger siblings. We then combine the birth order variation with within-municipality variation in respiratory disease prevalence among preschool-aged children to identify differential long-term impacts of early-life respiratory illness between younger and older siblings. We find that moving from the 25 th to the 75th percentile in the local disease prevalence distribution ("disease index") is associated with a 30.9 percent differential increase in the number of respiratory illness hospitalizations in the first year of life for younger compared to older siblings. In the long term, for younger relative to older siblings, we find a 0.5 percent differential reduction in the likelihood of high school graduation, and a 1.3 percent additional reduction in age-30 earnings.
\end{abstract}

\author{
N. Meltem Daysal \\ Department of Economics and CEBI \\ University of Copenhagen \\ Øster Farimagsgade 5 \\ 1353 Copenhagen \\ Denmark \\ and CEBI and IZA \\ meltem.daysal@econ.ku.dk \\ Hui Ding \\ Stanford University \\ khding@stanford.edu
}

\author{
Maya Rossin-Slater \\ Department of Health Policy \\ Stanford University School of Medicine \\ 615 Crothers Way \\ Encina Commons, MC 6019 \\ Stanford, CA 94305-6006 \\ and NBER \\ mrossin@stanford.edu \\ Hannes Schwandt \\ School of Education and Social Policy \\ Northwestern University \\ 2120 Campus Drive \\ Evanston, Il 60208 \\ and NBER \\ schwandt@northwestern.edu
}




\section{Introduction}

The societal costs of infectious disease are often measured in terms of their direct and immediate impacts on public health and economic activity (Adda, 2016). The COVID-19 pandemic serves as an extraordinary exposé of these costs, inspiring a vast body of research that attempts to quantify them. ${ }^{1}$ However, less attention has been paid to the costs of more common "run-of-the-mill" viruses that frequently circulate in the population, especially when it comes to their potential long-term consequences for human capital and economic outcomes.

This paper focuses on respiratory illnesses and a population that is particularly vulnerable to being infected with them: infants under age one. We use Danish population-level administrative data on 35 birth cohorts to provide a comprehensive analysis of both the mechanisms through which infants become infected by respiratory viruses, as well as the consequences of early-life respiratory disease exposure for their later outcomes.

We begin by documenting a striking disparity in the likelihood of severe respiratory disease in early childhood by birth order. Using data on all first- and second-born siblings born in Denmark between 1980 and 2015, we find that younger siblings have two to three times higher rates of hospitalization for respiratory conditions during their first year of life compared to the older siblings at the same age, and that this gap is particularly large when hospitalizations are measured in the first three months of life. ${ }^{2}$ Moreover, the hospitalization disparity is larger if the younger sibling is born in the fall or winter, when respiratory viruses circulate more frequently. The hospitalization gap is also larger for siblings with shorter birth spacing, who may be more prone to close contact that facilitates virus transmission. These patterns highlight the family unit as being central in virus transmission, and the hitherto under-studied mechanism by which birth order might influence children's longer-term outcomes - older children "bring home" common viruses (e.g., from group childcare environments), putting their younger siblings at heightened risk of severe respiratory illness in the first few months of life.

\footnotetext{
${ }^{1}$ The website ClinicalTrials.gov indicates that there are 6,646 registered studies on COVID-19 as of September 28, 2021. The National Bureau of Economic Research reports that there are over 500 economics studies about the pandemic (see https://www.nber.org/topics/covid-19).

${ }^{2}$ Note that this finding builds on several prior studies that document that higher-order siblings have better health outcomes at birth than first-borns (e.g., Brenøe and Molitor, 2018; Pruckner et al., 2021). Thus, it appears that younger children are more susceptible to severe respiratory infection, despite having better health at birth than their older counterparts.
} 
While younger siblings are clearly more likely to experience severe respiratory illness in the first few months of life than their older counterparts, the long-term impacts of this differential likelihood of illness are ambiguous. On the one hand, the expansive literature on a wide range of adverse shocks in early childhood documents lasting damages to human capital formation and other measures of adult well-being (Currie and Almond, 2011; Almond et al., 2018). On the other hand, evolutionary biology studies highlight the importance of physiological adaptation - i.e., that adverse shocks can lead to beneficial biological adaptations in humans (Bateson et al., 2014; Gluckman and Hanson, 2006) - and identify a high rate of immune system learning in the first year of life (Holt and Jones, 2000; M'Rabet et al., 2008; Côté et al., 2010). Thus, exposure to an infectious disease in infancy may increase immunity for an individual if they are exposed to the same virus at older ages, suggesting a potentially nonlinear relationship between early-life exposure and long-term outcomes (Fink et al., 2021). This type of immunity formation is particularly important for understanding the impacts of endemic viruses to which children are exposed on a regular basis.

To identify the long-term causal impacts of early-life respiratory disease exposure, we combine the birth order variation in the likelihood of severe respiratory infection together with variation in local disease prevalence. Local respiratory disease prevalence among children is largely driven by highly infectious conditions, such as the Respiratory Syncytial Virus, or RSV, which spread across locations in irregular waves (Pitzer et al., 2015). ${ }^{3}$ We construct a municipality-level index, which is designed to capture respiratory disease exposure during each child's first year of life from slightly older children in the community. We calculate the number of hospitalizations for respiratory conditions per 100 children aged 13 to 71 months in each municipality, and then assign to each child the cumulative child hospitalization rate in their municipality over their first 12 months of life. ${ }^{4}$ We then use our sample of siblings to estimate the differential effect of the respiratory disease index for younger compared to older siblings. Our regressions control for birth order, municipality, and birth-year-month

\footnotetext{
${ }^{3}$ As demonstrated by Pitzer et al. (2015), climatic factors - including temperature, vapor pressure, precipitation, and potential evapotranspiration - are important predictors of geographic variation in RSV transmission rates. While these factors may have impacts on long-term outcomes through channels unrelated to respiratory disease spread (see, e.g., Isen et al., 2017a, for evidence on early-life exposure to extreme temperature), we note that such channels are unlikely to differentially influence first versus second-born children.

${ }^{4}$ If a given child has an older sibling who is between 13 and 71 months of age during their first year of life, we exclude the older sibling from the hospitalization rate.
} 
fixed effects, thus accounting for other differences between older and younger siblings, timeinvariant differences across municipalities that might drive differences in disease exposure, and aggregate and seasonal trends in respiratory illness.

We show that the local respiratory disease index strongly predicts the likelihood that a child is hospitalized for a respiratory illness during the first year of life, and that this impact is much larger for younger relative to older siblings. We find that moving from the 25th to the 75th percentile in the disease index distribution is associated with a 0.021 differential increase in the number of respiratory illness hospitalizations in the first year of life for younger relative to older children, representing an additional 30.9 percent increase at the sample mean. This effect is in part driven by a differential increase in hospitalizations for RSV, which is a mild illness in most older children but can be extremely serious among infants. ${ }^{5}$

In the long run, the increased exposure to severe respiratory illness during infancy among second-born children translates into worse educational and labor market outcomes for them. We find that, for the younger siblings, moving from the 25th to the 75 th percentile in the disease index distribution is associated with a 0.4 percentage point ( 0.5 percent) differential decline in the likelihood of high school graduation, and a 1.3 percent additional reduction in earnings at age 30 .

We also examine the impacts of respiratory illness exposure in the first year of life on hospitalizations for respiratory conditions in later childhood. We find that higher respiratory disease exposure before age one is associated with a lower likelihood of hospitalization for all respiratory conditions at ages three to four, consistent with the hypothesis of immunity formation. We do not, however, observe a protective effect of first-year-of-life RSV exposure on the likelihood of RSV hospitalization during later childhood. This result is consistent with RSV not being an immunizing disease - that is, an RSV infection does not provide immunity against future illness. This lack of immunity formation, combined with the fact that RSV accounts for a large share of all respiratory hospitalizations during infancy (30 percent among second-born children), suggests that RSV might play a particularly important role in driving

\footnotetext{
${ }^{5}$ In most healthy individuals, RSV causes mild, cold-like symptoms. But in infants, RSV can cause severe respiratory infections, including bronchiolitis and pneumonia. Recent estimates suggest that approximately 14.7 per 1,000 infants under six months of age and 2.9 per 1,000 children under age five are hospitalized with RSV every year (Rha et al., 2020). For comparison, the COVID-19 hospitalization rate for children ages 0-4 is estimated to be 0.6 per 1,000 (see: https://gis.cdc.gov/grasp/covidnet/covid19_3.html).
} 
adverse long-term impacts on educational and economic outcomes. ${ }^{6}$

The lack of a differential increase in hospitalizations in later childhood for younger siblings further suggests that the long-run impacts that we estimate are unlikely to be solely driven by worse health in later childhood. Indeed, the long-run effects likely reflect both biological channels and parental responses (Almond and Mazumder, 2013; Yi et al., 2015; Adhvaryu and Nyshadham, 2016; Daysal et al., 2020; Pruckner et al., 2021). ${ }^{7}$

Lastly, we analyze heterogeneous impacts across different sub-groups of our sample based on parental socio-economic status, child health at birth, sibling gender composition, and child birth spacing. We find similar estimates across all sub-groups with one important exception: low birth weight younger siblings (those with birth weight less than 2,500 grams) experience a much larger differential increase in hospitalizations for respiratory conditions during the first year of life.

This study contributes to an expansive body of work on the human capital impacts of early life circumstances (Barker, 1990; Currie and Almond, 2011; Black et al., 2017; Almond et al., 2018). This literature includes estimates of the impacts of a vast range of prenatal and early childhood factors - from economic resources (e.g., Hoynes et al., 2016; Bailey et al., 2020) to nutrition (e.g., Almond and Mazumder, 2011) to environmental conditions (e.g., Almond et al., 2009; Isen et al., 2017b; Black et al., 2019) to maternal stress (e.g., Black et al., 2016; Persson and Rossin-Slater, 2018). The literature on infectious diseases in early childhood has focused on severe and often life-threatening infectious diseases, such as malaria and polio, that have been largely eradicated in high-income countries but still exist in the developing world (Bleakley, 2010; Barreca, 2010; Cutler et al., 2010; Lucas, 2010; Venkataramani, 2012; Chang et al., 2014; Barofsky et al., 2015; Gensowski et al., 2019; Kuecken et al., 2021; Fink et al., 2021), and on large-scale pandemics like the 1918 Spanish Flu (Almond, 2006; Almond and

\footnotetext{
${ }^{6}$ Unfortunately, we cannot measure the long-term effects of RSV illness directly. Our long-run analysis uses cohorts born in 1980-1989, whom we can observe through age 30 in the data. But Denmark used the International Classification of Disease version 8 (ICD-8) coding system until 1994, which does not contain a diagnostic code for RSV specifically. We can only measure RSV exposure for cohorts born in 1994 and later, when Denmark switched to the ICD-10 system.

${ }^{7}$ If parents engage in compensating responses - i.e., investing more in the younger child in response to the health shock - then our effect sizes would reflect under-estimates of the "true" biological impact of respiratory disease in infancy. If parents engage in reinforcing responses - i.e., investing less in the younger child in response to the health shock - then our effect sizes would be over-estimates of the "true" biological impact. We unfortunately do not have any data on parental behaviors to disentangle these two possibilities empirically.
} 
Mazumder, 2005; Lin and Liu, 2014) and the 1957 Asian Flu (Kelly, 2011). Schwandt (2018)'s analysis is an exception in that it focuses on the impacts of exposure to an endemic respiratory virus - the seasonal influenza - but only during the in utero period. Our study builds on this work by studying a range of respiratory illnesses that circulate among young children on a regular basis, and by focusing on the first year of life instead of the prenatal stage. ${ }^{8}$ Our novel estimates of long-term impacts of severe respiratory disease can inform cost-benefit evaluations of policies designed to curb transmission of common viruses, including vaccination mandates, drug distribution programs, and sick pay regulations (Bhalotra and Venkataramani, 2015; White, 2019; Pichler and Ziebarth, 2020; Bütikofer and Salvanes, 2020).

Our analysis further contributes to the literature on birth order and sibling spillovers, which has documented worse human capital and life outcomes for later-born children relative to firstborns (Black et al., 2005; Price, 2008; De Haan, 2010; Buckles and Kolka, 2014; Brenøe and Molitor, 2018; Lehmann et al., 2018; Breining et al., 2020; Black et al., 2021). This literature typically points to family resources and uneven parental investments as drivers of younger siblings' disadvantage. Our results suggest that the disease environment during infancy is an additional source of disadvantage for later-born children, and that the older sibling likely serves as a vector of transmission. Importantly, the long-term effects we measure are net of any parental responses to the health shocks. To the extent that parents may respond to one child's sickness in a compensatory way - as found by Yi et al. (2015) and Daysal et al. (2020) - the sibling differences in long-run outcomes that we find represent lower bounds of the raw (i.e., biological) impact of respiratory illness during infancy on later well-being.

Finally, this study is also relevant for the assessment of the costs of the COVID-19 pandemic for young children. While children have largely not been considered to be a high-risk group in terms of infection with the SARS-CoV-2 virus, the pandemic may have lasting and dynamic impacts on children through its effects on other infectious diseases. Policies implemented during the pandemic - including travel restrictions and school closures - have reduced the spread of other respiratory viruses, including RSV (Leung et al., 2020; Cowling et al.,

\footnotetext{
${ }^{8}$ Studies in the medical literature have analyzed the health impacts of RSV infection, with a focus on asthma as an outcome. These studies use relatively small samples of children to correlate RSV infection (or RSV hospitalization) with later health conditions (e.g., Kneyber et al., 2000; Korppi et al., 2004; Kusel et al., 2007; Régnier and Huels, 2013; Zomer-Kooijker et al., 2014; Carbonell-Estrany et al., 2015). We are not aware of studies using quasi-experimental designs to isolate causal impacts of early life RSV exposure, or those using population-level administrative data.
} 
2020). Our results suggest that some infants with older siblings - who would have otherwise been exposed to RSV during their first few months of life due to their older siblings bringing home these infections - may experience lasting benefits from the pandemic-induced protection from RSV.

At the same time, while the pandemic restrictions have led to a short-term reduction in infectious disease exposure among infants, the intertemporal dynamics of disease spread imply that there could be an increase in disease burden over the coming years. Epidemiological models predict that pandemic periods with muted spread of common infectious diseases are followed by stronger outbreaks (Baker et al., 2020). In fact, RSV cases have been surging following the removal of COVID-19 restrictions in summer 2021. ${ }^{9}$ This surge likely reflects the larger than usual susceptible population of young children who have been shielded from common viruses during the pandemic and thus have not yet built up their immune systems (Leung et al., 2020; Cowling et al., 2020; Huang et al., 2021). Thus, the COVID-19 pandemic may have important long-term effects on children through its dynamic impacts on the spread of other infectious diseases that are more serious in early life, including common respiratory viruses such as RSV.

\section{Data and Sample}

We use population register data from Denmark for the years 1980 to 2015. These data include individual-level records with unique personal identifiers that allow us to follow individuals over time and to link family members to one another.

Outcome variables. As outcomes, we study hospitalizations during childhood, as well as measures of long-term educational achievement and economic well-being.

More specifically, our key short-run outcome is the number of hospitalizations with a respiratory disease diagnosis during the first year of life. We measure this outcome using the National Patient Register, which includes all inpatient admissions to public and private hospitals, along with International Classification of Disease (ICD) diagnosis and procedure

\footnotetext{
${ }^{9}$ In July 2021, the Centers for Disease Control and Prevention issued a health advisory about an unusual surge in RSV cases among young children: https://emergency.cdc.gov/han/2021/han00443. asp.
} 
codes (Lynge et al., 2011). We classify inpatient visits with the following primary diagnosis codes as respiratory disease-related: ICD-8 codes starting with "46," "47," "48," "490," "079," and "783"; and ICD-10 codes starting with "B974" or "J" (excluding "J4"). We also examine hospitalizations for RSV specifically for cohorts born in 1994 onwards, which we identify with ICD-10 codes J12.1 (respiratory syncytial virus pneumonia), J20.5 (acute bronchitis due to respiratory syncytial virus), J21.0 (acute bronchiolitis due to respiratory syncytial virus), and B97.4 (respiratory syncytial virus as the cause of diseases classified elsewhere). ${ }^{10}$

For educational outcomes, we consider 9th grade test scores and educational attainment by age 30. Test scores come from the Academic Achievement Register, which exists from 2001 onward. We consider Danish (reading) and mathematics test scores separately, and standardize the scores within subject and test year such that they have a mean of zero and a standard deviation of one. Educational attainment comes from the Education Register 1981-2019, which contains the highest level of completed schooling from administrative school records. We create indicators for having a high school or a college degree by age 30 .

Finally, we use two registers to measure labor market outcomes at age 30 . We use the Register-Based Labour Force Statistics 1980-2019 to characterize employment status. This data set is based on tax records, and records the employment status of the entire Danish population (observed on January 1st) as of November of the preceding year (Petersson et al., 2011). We construct an indicator equal to one if an individual is employed and zero otherwise (i.e., those who are unemployed and those who are out of the labor force are both coded as zero). We also use the Income Statistics Register 1980-2019 to calculate the natural log of gross personal income at age 30, converted into 2010 \$USD.

Control variables. We observe a rich set of child and parent characteristics, using the previously defined registers as well as the Population Register and the Birth Register. The Population Register provides a snapshot of demographics on all Danish residents as of January 1st of each year (Pedersen, 2011). The Birth Register includes the universe of births, with information on the exact date of birth, gender, plurality, and birth weight. It also has unique

\footnotetext{
${ }^{10}$ Denmark switched from the ICD-8 system to the ICD-10 system in 1994 . The ICD-8 system did not have any codes specific to RSV.
} 
parental identifiers, allowing us to link siblings and determine birth order. ${ }^{11}$

Some of our specifications include the following variables as controls, measured at the time of childbirth: child gender, maternal age, maternal foreign-born status, maternal education level, and parental marital/cohabitation status. We also include controls for the natural $\log$ of the mother's, father's, and the family's total income, as well as parental labor force participation, all measured in the year before childbirth.

Analysis sample. To construct our analysis sample, we begin with the universe of 2,221,433 children born between 1980 and 2015 in Denmark and make the following restrictions. First, we exclude families with only one child. Second, we only keep the first and second-born children in every family, and further, we only keep families in which the first and second-born children are singletons. Third, we only keep children in sibling pairs with a birth spacing gap of at least 11 months, which ensures that there is no overlap in the first year of life of the two children. Fourth, we only keep children with non-missing information on municipality of birth and who are born in municipalities that have an average of at least 1,000 children aged 13-71 months over the sample period, which ensures that we have sufficient observations to calculate the respiratory disease exposure index as described in Section 3 below. ${ }^{12}$ Finally, we drop children with missing parental control variables, and keep sibling pairs in which both children remain in the sample after these restrictions.

Our final analysis sample consists of 1,176,746 children, which we use to analyze shortterm impacts of respiratory disease exposure on hospitalizations in the first year of life. When studying long-term outcomes, our sample sizes differ depending on the ages at which outcomes are measured. To study test scores, we use children born between 1986 and 2003 because test score data begin in 2001 and we need to observe children when they are in ninth grade (around age 16). To study educational attainment and labor market outcomes at age 30, we analyze children born between 1980 and 1989.

\footnotetext{
${ }^{11}$ Specifically, the birth records contain identifiers for all mothers. If the mother is married at the time of childbirth, then her husband is automatically registered as the biological father. If the mother is unmarried, then the biological father's identifier is listed if he establishes paternity. Fathers' identifiers are missing for only $0.58 \%$ percent of observations in our analysis period.

${ }^{12}$ This restriction leads us to drop children born in eight small municipalities.
} 


\section{Descriptive Analysis and Empirical Design}

\subsection{Differences in Respiratory Disease Hospitalizations between Older and Younger Siblings}

Our goal is to analyze the causal effects of respiratory disease in the first year of life on health, educational, and economic outcomes. To motivate our empirical design, we begin with a descriptive analysis of respiratory disease hospitalization patterns among children in our sample, comparing first- and second-born siblings. This analysis sheds light on a likely mechanism through which respiratory diseases spread within families - older children, most of whom interact with same-age peers in group childcare settings and are therefore frequently exposed to infectious viruses, "bring home" diseases that infect their younger siblings.

Raw sibling differences. Panel (a) of Figure 1 plots the average number of respiratory disease hospitalizations (per 100 children) by child age in months during the first year of life. It shows that, compared to first-born children, younger siblings have two to three times higher rates of hospitalization for respiratory disease, and that the difference is especially large when children are two and three months of age. Panel (b) of Figure 1 extends the time horizon on the $x$-axis to 60 months (i.e., age five), and demonstrates that the difference in hospitalization rates between older and younger siblings disappears after age one. This pattern is consistent with the vast majority of Danish children staying home with their mothers during their first year of life, and only starting to attend group childcare after they turn one year old. ${ }^{13}$ Thus, after age one, younger and older siblings are similarly likely to be exposed to infectious viruses in group care environments, whereas non-first-borns have exposure before they turn one through their older siblings bringing home viruses.

Seasonal differences. In Figure 2, we explore the role of respiratory disease seasonality in driving the observed hospitalization gap between siblings. The two graphs in Figure 2 show

\footnotetext{
${ }^{13}$ In Denmark, some form of maternity leave has been available since the beginning of the 20th century. In 1980, mothers had access to 14 weeks of nearly fully paid leave following the birth of a child, and this leave benefit was extended to 24 weeks (and also began to include fathers) in 1985 (Rasmussen, 2010). Subsequently, additional weeks of leave were added with reduced benefit compensation. By 2002, new parents could receive up to 52 weeks of parental leave with partial pay. The majority of this leave is used by mothers (see, e.g., Beuchert et al., 2016).
} 
the average number of respiratory disease hospitalizations for older and younger siblings, respectively, separately by season of birth. These graphs reveal three facts. First, children are more likely to be hospitalized for respiratory disease during the winter when common respiratory disease outbreaks (such as RSV) are more prevalent - children born in November, December, and January have highest hospitalization rates in the first three months of life; those born in August, September, and October have highest hospitalization rates at 3 to 6 months old; those born in May, June, and July have highest hospitalization rates at 7 to 9 months old; and those born in February, March, and April have highest hospitalization rates at 10 to 12 months old. Second, younger siblings have higher hospitalization rates than older siblings regardless of season of birth. Third, out of all sub-groups considered, younger siblings born in the winter months have the highest hospitalization rates when they are two to three months old, suggesting that they are particularly susceptible to severe respiratory infections during early infancy.

Birth spacing differences. Lastly, in Figure 3, we examine differences in these patterns across siblings with different birth spacing gaps. Each graph plots the average number of respiratory disease hospitalizations per 100 children by age in months of the older siblings (on the left) and the younger siblings (on the right), separately by season of birth and for different birth spacing gaps. The graphs demonstrate that younger siblings born in winter months have the highest hospitalization rates regardless of birth spacing, and that the difference in hospitalizations between younger and older siblings gets much smaller as birth spacing increases. This pattern is consistent with siblings having more interactions that facilitate disease spread when their age difference is smaller, and with the older siblings - i.e., the ones who "bring home" disease-being more susceptible to infection when they are younger themselves (since the age of the older siblings observed in the right-hand graphs in Figure 3 falls when the birth spacing gap is smaller).

In sum, the observed patterns in the data-(i) higher hospitalization rates among younger siblings than older siblings, (ii) a larger sibling hospitalization gap during the winter season, and (iii) a larger hospitalization gap for more closely spaced siblings - are consistent with the idea that respiratory disease spreads within the family because older children "bring home" 
viruses that they pick up in their local community (e.g., at their childcare center). This analysis informs our empirical strategy for estimating the causal effects of early childhood respiratory disease exposure: We focus on exposure during the first year of life, leverage variation in local respiratory disease outbreaks among slightly older children, and analyze differential effects across older versus younger siblings.

\subsection{Empirical Strategy for Estimating Causal Effects of Early Life Respiratory Disease Exposure}

Our main independent variable is designed to capture respiratory disease exposure during the first year of life from slightly older children in the local community. We begin by using the National Patient Register data to obtain the number of respiratory disease hospitalizations per 100 children aged 13 to 71 months in each municipality and calendar year-month over our analysis time frame. ${ }^{14}$ To allow for an informative visualization of the variation in this respiratory hospitalization rate, in Appendix Figure A1, we plot the raw month-by-month values of the rate in each of Denmark's 15 most populated municipalities over the period of January 1988 to December 1992. Consistent with our descriptive analysis above, we observe a strong seasonal pattern, with a higher hospitalization rate during the winter months in all locations. At the same time, there is a substantial amount of variation in children's respiratory hospitalizations across municipalities in any given month, as well as within each municipality over time. In Appendix Figure A2, we demonstrate the central source of variation used to identify the key estimates in our empirical model (described in more detail below) — we use data for all municipalities in Denmark for the entire sample period, regress the hospitalization rate on municipality and year-month fixed effects, and plot the distribution of the residuals. The figure demonstrates that there remains a substantial amount of variation in respiratory disease hospitalizations even after location and time fixed effects are partialled out.

Next, for each child in our sibling analysis sample, we assign this monthly respiratory hospitalization rate to each month of their first year of life based on their municipality of residence in that month. Importantly, if a given child has an older sibling who is between 13

\footnotetext{
${ }^{14}$ We use 71 months (i.e., 5 years and 11 months) as the upper age limit to capture respiratory disease spread among preschool-aged children, most of whom are in group childcare environments. Children start primary school at age 6 in Denmark.
} 
and 71 months of age at any point during their first year of life, we exclude the older sibling from the hospitalization rate. Finally, we define the disease exposure index as the sum of the monthly hospitalization rates over the 12 months of each child's first year of life. Thus, our index captures a child's cumulative respiratory disease exposure before age one from slightly older children in their municipality. While our baseline models include all hospitalizations with a primary diagnosis of a respiratory condition in the index, in some analyses, we also use an index that only includes hospitalizations for RSV.

Our empirical models estimate the differential effect of the respiratory disease exposure index on younger versus older siblings. Specifically, our regression models take the form:

$$
Y_{i t m}^{a}=\beta_{0}+\beta_{1} \text { Younger }_{i}+\beta_{2} \text { Index }_{i t m}+\beta_{3} \text { Younger }_{i} \times \text { Index }_{i t m}+\mu_{m}+\theta_{t}+\gamma^{\prime} X_{i}+\epsilon_{i t m}
$$

for each child $i$ born in year-month $t$ in municipality $m . Y_{i t m}^{a}$ is an outcome measured at age a. Younger $_{i}$ is an indicator set to 1 for younger siblings, and captures birth order effects on our outcomes of interest. Index $x_{i t m}$ is the respiratory disease exposure index described above. $\mu_{m}$ are municipality fixed effects that account for time-invariant geographic differences in exposure to infectious diseases and in other determinants of our outcomes. $\theta_{t}$ are year and month of birth fixed effects that control for cohort trends. $X_{i}$ is a vector of individual and family background control variables measured in the year of birth: indicator for the child being male, mother's age and age squared, indicators for mother's education level (less than high school, high school degree, college degree or higher), and an indicator for parents being married or cohabiting. We also control for the natural log of the mother's, father's, and total family income, as well as indicators for each parent being in the labor force, in the year before childbirth. We cluster standard errors on the municipality level.

Identifying assumption. The key coefficient of interest in model (1), $\beta_{3}$, measures the differential impact on younger siblings relative to older siblings of an additional respiratory disease hospitalization per 100 children aged 13-71 months in the child's municipality during their first year of life. Interpreting this coefficient as representing a causal impact of respiratory disease exposure relies on an assumption that there are no unobserved municipality-specific time-varying factors that are (a) correlated with respiratory disease prevalence, (b) influence 
children's outcomes, and (c) differentially impact younger versus older children in a family. While this assumption is not directly testable, we assess its plausibility in several ways.

First, we investigate the sensitivity of our main results across specifications that include various controls, including municipality-specific linear trends and mother fixed effects. As we show below, our results are generally robust across these models.

Second, we estimate model (1) without the controls in $X_{i}$ and instead using the $X_{i}$ variables as outcomes (Pei et al., 2019). Results are presented in Appendix Table A1. We find that only one out of the 11 interaction coefficients reported in this table is statistically significantmothers of younger siblings are slightly older in municipalities with higher respiratory disease exposure indices. We control for maternal age in all of our analyses.

Third, we construct two indices based on non-infectious diseases, in which instead of using children's hospitalizations for respiratory conditions, we instead use: (i) non-infectious digestive diseases, and (ii) injuries and poisonings. If the differential likelihood of hospitalization for respiratory conditions for younger compared to older children reflects differences in parental healthcare-seeking behavior (i.e., parents are more likely to go to the hospital with their second-born than their first-born at the same level of underlying illness), then we might expect similar patterns to emerge for other non-infectious childhood health shocks, such as digestive issues or accidents. Yet when we estimate model (1) using the two placebo indices and hospitalizations in the first year of life for these causes, we do not find evidence in support of this hypothesis (see Appendix Tables A2 and A3). If anything, we find that younger children are less likely to be hospitalized for these causes, and there is no evidence of a significant interaction between the placebo index and the younger child indicator. ${ }^{15}$

Finally, we analyze whether our respiratory disease index differentially predicts hospitalization rates for non-infectious conditions for younger versus older siblings. When we estimate model (1) with hospitalizations for non-infectious digestive diseases and for injuries and poisonings in the first year of life as dependent variables, we do not find any evidence of a positive interaction coefficient between the disease index and the younger sibling indicator (see Appendix Tables A4 and A5, respectively). If anything, it appears that younger siblings are

\footnotetext{
${ }^{15}$ Note the fact that we observe main effects of the placebo indices on hospitalizations for the same causes makes sense, as they are likely driven by underlying local and seasonal factors (e.g., icy conditions may increase the local injury rate among kids).
} 
differentially somewhat less likely to be hospitalized for these causes when the respiratory disease index is higher (although the interaction coefficients are only marginally significant, and only in some of the models).

Overall, these analyses support our identifying assumption, and suggest that our model is likely to yield causal estimates of the differential effects of respiratory disease exposure in early childhood for younger relative to older siblings.

Sample means. Table 1 presents means of some of the key variables in our analysis, separately for the older and younger siblings in the sample. The first panel highlights some differences in child outcomes by birth order. Compared to older siblings, younger siblings have higher average birth weight (3588.4 versus 3430.7 grams for younger versus older siblings, respectively). The average values of the respiratory disease exposure index for older and younger siblings are similar: 2.8 and 2.9 hospitalizations per 100 children, respectively. However, despite the slight advantage in health at birth (which has been found in other settings, see, e.g. Brenøe and Molitor, 2018; Pruckner et al., 2021) and similar local exposure to respiratory disease, younger siblings' average number of hospitalizations for respiratory conditions during their first year of life is nearly twice the average for older siblings (0.090 and 0.047 for younger and older siblings, respectively). The relative difference is even larger for RSV hospitalizations during the first year of life, with younger siblings' average number of hospitalizations three times higher relative to older siblings. ${ }^{16}$ Moreover, consistent with prior literature on the impacts of birth order (e.g., Black et al., 2005), younger siblings have lower academic and economic outcomes than their older counterparts.

The second panel shows that mothers are on average aged 26.8 years at the time of their first birth and 30.3 years at the time of their second birth. Approximately 4.5 percent of mothers in our sample are foreign-born. About 75.1 and 78.9 percent of mothers have a high school degree at the time of the first and second birth, respectively, while 30.2 and 36.8 percent have a college degree, respectively. Approximately 80 percent of parents are married or cohabiting at the time of the first birth, while 93.8 percent are married or cohabiting at

\footnotetext{
${ }^{16}$ The average number of hospitalizations for all respiratory conditions among the 1994+ cohorts, for whom we observe RSV-specific hospitalizations, is similar to the overall sample that includes older cohorts: 0.099 and 0.045 for younger and older siblings, respectively.
} 
the time of the second. Household income is slightly higher at the time of the second than the first birth.

\section{Results}

\section{Effects of local respiratory disease exposure on children's respiratory hospitaliza-}

tions. Panel A of Table 2 presents results from estimating equation (1) using as the outcome the number of hospitalizations during the first year of a child's life that have a primary diagnosis of a respiratory condition. We report the coefficients on the indicator denoting the younger sibling, the respiratory disease exposure index (expressed as the number of respiratory disease hospitalizations per 100 children aged 13 to 71 months), and the interaction of these two variables. Column (1) shows that, consistent with the graphical evidence in Figures 1 through 3 , younger siblings on average have 0.039 more (57.4 percent relative to the sample mean) hospitalizations for a respiratory condition before age one than their older counterparts. Column (2) shows that there is a positive correlation between the disease exposure index and the likelihood of hospitalization before age one in the overall siblings sample, and column (3) demonstrates that the coefficients on the younger sibling indicator and the disease exposure index do not change when they are both included in the same regression model. Once we include the interaction term in columns (4) and (5), we find that there is a significant differential effect of local respiratory disease exposure on younger siblings relative to older siblings. In particular, we find that an additional respiratory hospitalization per 100 children aged 13-71 months in a municipality increases the younger sibling's number of hospitalizations during the first year of life by an average of 0.012 (18 percent), as compared to the older sibling. This relationship is robust across specifications without and with family background control variables (columns 4 and 5, respectively). In the bottom row of the table, we report the magnitude of the differential effect on younger siblings relative to older siblings of an increase in the disease exposure index from the 25 th to the 75 th percentile of the index distribution. This magnitude amounts to a 0.021 differential increase in the number of respiratory disease hospitalizations in the first year of life, which represents an additional 30.9 percent relative to the sample mean. 
We also use the RSV-specific index to analyze RSV hospitalizations in the first year of life in Panel B of Table 2, and find similar results in relative terms. We estimate that an additional RSV hospitalization per 100 children aged 13-71 months in a municipality increases a younger child's number of RSV hospitalizations in the first year of life by an average of 0.046 more than their older sibling's RSV hospitalizations at the same age. Moving from the 25th to the 75th percentile of the RSV index distribution amounts to a 0.005 differential increase in the number of RSV hospitalizations, or 27.8 percent at the sample mean.

\section{Effects of local respiratory disease exposure before age one on long-term outcomes.}

Having established that local respiratory disease exposure among slightly older children predicts children's own hospitalizations for respiratory conditions before age one, and that this effect is much larger for younger relative to older siblings, we proceed to analyze children's long-term educational and economic outcomes.

Tables 3 and 4 present results for high school and college graduation by age 30, respectively. We find an overall birth order effect-younger siblings are on average 5.1 and 9.0 percentage points less likely to graduate high school and college, respectively, than their older counterparts. We do not observe an overall effect of early life disease exposure on these outcomes - the coefficients on the disease exposure index in columns (2) and (3) are very small in magnitude and insignificant. At the same time, column (4) shows that the younger siblings experience an adverse effect of early life respiratory disease exposure on educational attainment compared to older siblings, at least when it comes to the likelihood of high school graduation (Table 3). In particular, column (4) of Table 3 shows that moving from the 25 th to the 75 th percentile in the respiratory disease exposure index distribution is associated with an additional 0.4 percentage point reduction in the likelihood of high school graduation for younger siblings relative to older siblings. ${ }^{17}$

Tables 5 and 6 report results for labor force participation and log income (conditional on

\footnotetext{
${ }^{17}$ We also present results using as outcomes standardized 9th grade Danish and math test scores in Appendix Tables A6 and A7, respectively. We find suggestive evidence that younger children experience a differential penalty from local respiratory disease exposure in early life. An additional respiratory hospitalization in the municipality per 100 children aged 13-71 months reduces the 9th grade Danish test score by about 0.009 of a standard deviation more for younger siblings than older siblings (this coefficient is marginally significant at the $10 \%$ level). The 25 th to 75 th percentile increase in the disease index amounts to an additional 0.016 of a standard deviation penalty on the Danish test score for the younger siblings relative to the older siblings. We do not observe a statistically significant impact on math test scores.
} 
being employed) at age 30. Again, consistent with the prior literature, younger siblings have worse labor market outcomes compared to their older counterparts. We do not observe any significant impact of early life respiratory disease exposure on labor force participation in Table 5 , but we do see a negative impact on income in Table 6, with younger siblings experiencing an additional penalty. Column (4) of Table 6 demonstrates that moving from the 25th to the 75th percentile in the respiratory disease exposure index distribution is associated with an additional 1.3 percent reduction in age-30 income (conditional on employment) for younger relative to older siblings.

Magnitudes. The magnitudes of the long-term effects of respiratory disease exposure during infancy that we find are comparable to the estimates of impacts of other early-life shocks found in the literature. Specifically, we show that moving from the 25 th to the 75 th percentile of the respiratory disease index distribution is associated with an additional 1.3 percent reduction in adult earnings for second-born children. This effect size is similar to the earnings impact of a 10 percent reduction in birth weight (Black et al., 2007) or a 10 percent increase in ambient air pollution in one's year of birth (Isen et al., 2017b). It also corresponds to about half of the effect of in utero exposure to the 1918 Spanish Influenza pandemic (Almond, 2006) and one-fifth of the effect of in utero exposure to a maternal influenza infection that requires hospitalization (Schwandt, 2018). ${ }^{18}$

It is additionally helpful to compare our estimates to those found in studies evaluating policies that reduce disease prevalence in the population. For example, Bhalotra and Venkataramani (2015) find that moving from the 75 th to the 25 th percentile in the pneumonia infection rate following the introduction of sulfa drugs leads to a 2.1 percent increase in adult income among exposed cohorts. Bütikofer and Salvanes (2020) document a 0.8 percent increase in adult income for cohorts who were in school during and after a tuberculosis control campaign in Norwegian municipalities that had above-median pre-campaign tuberculosis levels.

Lastly, we benchmark our estimates against the literature on birth order. In seminal work, Black et al. (2005) find an earnings disadvantage of 1.2 to 4.2 percent for second-born siblings compared to those who are first-born. Our birth order effect is within this range - we find a

\footnotetext{
${ }^{18}$ Note that our estimates represent intent-to-treat effects as not every child gets sick in response to exposure to a higher respiratory disease index.
} 
2.8 percent income penalty for younger compared to older siblings in regressions that exclude the interaction term between the respiratory disease index and the younger sibling indicator (see Columns (1) and (3) of Table 6). However, when the interaction term is included, the main effect of birth order decreases in magnitude and becomes statistically insignificant. This result suggests that an important part of the overall birth order effect on income could be explained by the second-born child's higher vulnerability to respiratory disease during infancy.

Differential effects by age of observation. Sub-figures (a) and (b) of Figure 4 plot the coefficients and $95 \%$ confidence intervals on our key variable - the interaction between the younger sibling indicator and the respiratory disease exposure index - from separate models that use as outcomes the annual number of respiratory disease hospitalizations and RSV hospitalizations, respectively, measured at different ages denoted on the $x$-axis. We use our preferred model with municipality and cohort fixed effects and family background controls. Consistent with results presented above, we find a large differential effect on hospitalizations before age one among younger siblings. However, this effect dissipates as we analyze hospitalizations at older ages. If anything, it appears that respiratory disease exposure in the first year of life is associated with a reduction in the number of overall respiratory hospitalizations at ages 3 to 4, although we do not see such a pattern for RSV hospitalizations specifically. This pattern of results is consistent with the immunity formation hypothesis (Holt and Jones, 2000; M'Rabet et al., 2008; Côté et al., 2010; Fink et al., 2021) for some respiratory conditions, but not others, such as RSV. At the same time, our findings suggest that the differential adverse effects on long-term educational and economic outcomes of early-life respiratory disease exposure among younger siblings are not driven solely by worse health in later childhood.

Figure 5 examines differential effects on educational attainment and labor market outcomes measured at ages 18 to 34 . The pattern of coefficients suggests that the negative differential effects on high school and college graduation for younger siblings are fairly stable from the age at which these outcomes can be affected (i.e., starting around age 19 for high school graduation, and age 23 for college graduation), although not all coefficients are statistically significant due to the smaller sample sizes that we rely on when studying older cohorts. For labor force participation, we observe a positive differential effect at ages 23 to 25, which is 
consistent with selection out of higher education and into work, and a null effect at later ages. For income conditional on being employed, little effect is found at ages 18-25, but the negative differential effect can be seen from age 26 onward.

Heterogeneous effects across sub-groups. Sub-figures (c) and (d) of Figure 4 present results from models estimated on different sub-samples of the data for our main short-run outcomes, the number of overall respiratory disease hospitalizations by age one and the number of RSV hospitalizations by age one, respectively. We consider differences in effects by parental socio-economic status (defined as the mother's years of education being above or below the median in the distribution), child health at birth (birth weight above and below the median, as well as low-birth-weight and non-low-birth-weight children), the gender composition of the siblings, and the birth spacing between the siblings. We find similar estimates across all subgroups, with one important exception: low birth weight children (those whose birth weight is below 2,500 grams) experience a much larger differential increase in respiratory disease hospitalizations and RSV-specific hospitalizations when they are the younger siblings. We have also analyzed heterogeneous impacts on long-term outcomes, but did not detect any significant differences across sub-groups, potentially due to lower sample sizes in these longrun analyses.

Sensitivity of results. We examine the sensitivity of our results across different specifications and different ways of measuring respiratory disease exposure in Appendix Tables A8 through A12. Specifically, for each our outcomes of interest, we estimate different versions of model (1). Column (1) of each table presents the baseline model where we have municipality and cohort fixed effects and family background controls. Column (2) drops family background controls. If the disease index is correlated with observed family characteristics, this would result in a change in the estimated interaction effect. The fact that the coefficient remains virtually unchanged suggests this is not the case, which also alleviates concerns about a potential bias due to a correlation with unobserved family characteristics. Column (3) adds municipality-specific linear time trends which control for unobserved municipality level factors that change over time, while column (4) adds mother fixed effects that eliminate a potential bias from unobserved genetic and family characteristics common among siblings. 
In our baseline analysis, our respiratory disease index is based on the number of hospitalizations with a primary diagnosis of a respiratory condition (or RSV). Columns (5) and (6) check the robustness of the results to alternative ways of constructing the disease index. Column (5) calculates the disease index based on number of hospitalizations including both primary and non-primary diagnoses for respiratory conditions, while in column (6) we construct it based on the number of children with at least one primary respiratory disease diagnosis (i.e., we count the number of children rather than the total number of hospitalizations). Our results are quite robust across these different modeling choices.

\section{Conclusion}

Respiratory illnesses are very common among young children, especially in families with more than one child. Despite their regular occurrence, there is limited population-level evidence on the role of intra-family transmission, or on the long-term causal impacts of exposure to endemic respiratory disease during infancy. This paper uses linked administrative data from Denmark spanning four decades to document the importance of birth order in driving susceptibility to respiratory infection. Specifically, we find that younger siblings are two to three times more likely to be hospitalized for respiratory conditions during their first year of life compared to the older siblings at the same age, and this disparity is especially large when

hospitalizations are measured in the first three months of life. Additional analyses of the seasonality in hospitalizations and heterogeneity across siblings with different birth spacing gaps point to the importance of intra-family transmission in explaining this birth order effect: older children "bring home" common respiratory viruses (such as RSV), making their younger siblings susceptible to severe illness early in life.

We then combine the birth order variation with variation in local respiratory disease prevalence to study long-term effects of early-life disease on human capital and economic outcomes. We show that exposure to severe respiratory illness during infancy has negative consequences on both educational and economic outcomes in adulthood. Our results show that moving from the 25 th to the 75 th percentile in the local respiratory disease prevalence distribution leads to a 0.5 percent differential reduction in the likelihood of high school graduation and a 1.3 
percent additional reduction in age-30 earnings for younger compared to older siblings.

The long-term effects that we estimate represent the overall net impacts of respiratory disease exposure during infancy. Thus, these estimates incorporate any potential benefits associated with increased immunity, as well as parental responses to the health shocks. In sum, our findings suggest that policies mitigating the spread of respiratory diseases among young children may have large long-term benefits, which are likely not incorporated into current cost-benefit evaluations.

\section{References}

Adda, Jérôme, "Economic activity and the spread of viral diseases: Evidence from high frequency data," The Quarterly Journal of Economics, 2016, 131 (2), 891-941.

Adhvaryu, Achyuta and Anant Nyshadham, "Endowments at birth and parents' investments in children," The Economic Journal, 2016, 126 (593), 781-820.

Almond, Douglas, "Is the 1918 influenza pandemic over? Long-term effects of in utero influenza exposure in the post-1940 US population," Journal of Political Economy, 2006, $114(4), 672-712$.

- and Bhashkar Mazumder, "The 1918 influenza pandemic and subsequent health outcomes: an analysis of SIPP data," American Economic Review, 2005, 95 (2), 258-262.

_ and _, "Health capital and the prenatal environment: the effect of Ramadan observance during pregnancy," American Economic Journal: Applied Economics, 2011, 3 (4), 56-85.

_ and _, "Fetal origins and parental responses," Annu. Rev. Econ., 2013, 5 (1), 37-56.

_ , Janet Currie, and Valentina Duque, "Childhood circumstances and adult outcomes: Act II," Journal of Economic Literature, 2018, 56 (4), 1360-1446.

_ , Lena Edlund, and Mårten Palme, "Chernobyl's subclinical legacy: prenatal exposure to radioactive fallout and school outcomes in Sweden," The Quarterly journal of economics, 2009, 124 (4), 1729-1772.

Bailey, Martha J, Hilary W Hoynes, Maya Rossin-Slater, and Reed Walker, "Is the social safety net a long-term investment? Large-scale evidence from the food stamps program," Working Paper w26942, National Bureau of Economic Research 2020.

Baker, Rachel E, Sang Woo Park, Wenchang Yang, Gabriel A Vecchi, C Jessica E Metcalf, and Bryan T Grenfell, "The impact of COVID-19 nonpharmaceutical interventions on the future dynamics of endemic infections," Proceedings of the National Academy of Sciences, 2020, 117 (48), 30547-30553. 
Barker, David J, "The fetal and infant origins of adult disease.," BMJ: British Medical Journal, 1990, 301 (6761), 1111.

Barofsky, Jeremy, Tobenna D Anekwe, and Claire Chase, "Malaria eradication and economic outcomes in sub-Saharan Africa: evidence from Uganda," Journal of health economics, 2015, 44, 118-136.

Barreca, Alan I, "The long-term economic impact of in utero and postnatal exposure to malaria," Journal of Human resources, 2010, 45 (4), 865-892.

Bateson, Patrick, Peter Gluckman, and Mark Hanson, "The biology of developmental plasticity and the Predictive Adaptive Response hypothesis," The Journal of physiology, 2014, 592 (11), 2357-2368.

Beuchert, Louise Voldby, Maria Knoth Humlum, and Rune Vejlin, "The length of maternity leave and family health," Labour Economics, 2016, 43, 55-71.

Bhalotra, Sonia R and Atheendar Venkataramani, "Shadows of the captain of the men of death: Early life health interventions, human capital investments, and institutions," Human Capital Investments, and Institutions (August 8, 2015), 2015.

Black, Maureen M, Susan P Walker, Lia CH Fernald, Christopher T Andersen, Ann M DiGirolamo, Chunling Lu, Dana C McCoy, Günther Fink, Yusra R Shawar, and Jeremy Shiffman, "Early childhood development coming of age: science through the life course," The Lancet, 2017, 389 (10064), 77-90.

Black, Sandra E, Aline Bütikofer, Paul J Devereux, and Kjell G Salvanes, "This is only a test? Long-run and intergenerational impacts of prenatal exposure to radioactive fallout," Review of Economics and Statistics, 2019, 101 (3), 531-546.

_, Paul J Devereux, and Kjell G Salvanes, "The more the merrier? The effect of family size and birth order on children's education," The Quarterly Journal of Economics, 2005, $120(2), 669-700$.

_ , _, and _ , "From the cradle to the labor market? The effect of birth weight on adult outcomes," The Quarterly Journal of Economics, 2007, 122 (1), 409-439.

$\ldots, \ldots$, and _ , "Does grief transfer across generations? Bereavements during pregnancy and child outcomes," American Economic Journal: Applied Economics, 2016, 8 (1), 193-223.

_, Sanni Breining, David N Figlio, Jonathan Guryan, Krzysztof Karbownik, Helena Skyt Nielsen, Jeffrey Roth, and Marianne Simonsen, "Sibling spillovers," The Economic Journal, 2021, 131 (633), 101-128.

Bleakley, Hoyt, "Malaria eradication in the Americas: A retrospective analysis of childhood exposure," American Economic Journal: Applied Economics, 2010, 2 (2), 1-45.

Breining, Sanni, Joseph Doyle, David N Figlio, Krzysztof Karbownik, and Jeffrey Roth, "Birth order and delinquency: Evidence from Denmark and Florida," Journal of Labor Economics, 2020, 38 (1), 95-142. 
Brenøe, Anne and Ramona Molitor, "Birth Order and Health of Newborns: What Can We Learn from Danish Registry Data?," Journal of Population Economics, 2018, 31, 363395.

Buckles, Kasey and Shawna Kolka, "Prenatal investments, breastfeeding, and birth order," Social Science Eamp; Medicine, 2014, 118, 66-70.

Bütikofer, Aline and Kjell G Salvanes, "Disease control and inequality reduction: Evidence from a tuberculosis testing and vaccination campaign," The Review of Economic Studies, 2020, 87 (5), 2087-2125.

Carbonell-Estrany, Xavier, Eduardo G Pérez-Yarza, Laura Sanchez García, Juana M Guzmán Cabañas, Elena Villarrubia Bòria, Belén Bernardo Atienza, and IRIS (Infección Respiratoria Infantil por Virus Respiratorio Sincitial) Study Group, "Long-term burden and respiratory effects of respiratory syncytial virus hospitalization in preterm infants - the SPRING study," PloS one, 2015, 10 (5), e0125422.

Chang, Simon, Belton Fleisher, Seonghoon Kim, and Shi yung Liu, "Long-Term Health Effects of Malaria Exposure around Birth: Evidence from Colonial Taiwan," Economic Development and Cultural Change, 2014, 62 (3), 519-536.

Côté, Sylvana M, Amélie Petitclerc, Marie-France Raynault, Qian Xu, Bruno Falissard, Michel Boivin, and Richard E Tremblay, "Short-and long-term risk of infections as a function of group child care attendance: an 8-year population-based study," Archives of pediatrics \& adolescent medicine, 2010, 164 (12), 1132-1137.

Cowling, Benjamin J, Sheikh Taslim Ali, Tiffany WY Ng, Tim K Tsang, Julian CM Li, Min Whui Fong, Qiuyan Liao, Mike YW Kwan, So Lun Lee, Susan S Chiu et al., "Impact assessment of non-pharmaceutical interventions against coronavirus disease 2019 and influenza in Hong Kong: an observational study," The Lancet Public Health, 2020, 5 (5), e279-e288.

Currie, Janet and Douglas Almond, "Human capital development before age five," in "Handbook of labor economics," Vol. 4, Elsevier, 2011, pp. 1315-1486.

Cutler, David, Winnie Fung, Michael Kremer, Monica Singhal, and Tom Vogl, "Early-life malaria exposure and adult outcomes: Evidence from malaria eradication in India," American Economic Journal: Applied Economics, 2010, 2 (2), 72-94.

Daysal, N Meltem, Marianne Simonsen, Mircea Trandafir, and Sanni Breining, "Spillover effects of early-life medical interventions," Review of Economics and Statistics, 2020, pp. 1-46.

Fink, Günther, Atheendar S Venkataramani, and Arianna Zanolini, "Early life adversity, biological adaptation, and human capital: evidence from an interrupted malaria control program in Zambia," Journal of Health Economics, 2021, 80, 102532. 
Gensowski, Miriam, Torben Heien Nielsen, Nete Munk Nielsen, Maya RossinSlater, and Miriam Wüst, "Childhood health shocks, comparative advantage, and longterm outcomes: Evidence from the last Danish polio epidemic," Journal of health economics, 2019, 66, 27-36.

Gluckman, Peter and Mark Hanson, Mismatch: Why our world no longer fits our bodies, Oxford University Press, 2006.

Haan, Monique De, "Birth order, family size and educational attainment," Economics of Education Review, 2010, 29 (4), 576-588.

Holt, PG and CA Jones, "The development of the immune system during pregnancy and early life," Allergy, 2000, 55 (8), 688-697.

Hoynes, Hilary, Diane Whitmore Schanzenbach, and Douglas Almond, "Long-run impacts of childhood access to the safety net," American Economic Review, 2016, 106 (4), 903-34.

Huang, Q Sue, Tim Wood, Lauren Jelley, Tineke Jennings, Sarah Jefferies, Karen Daniells, Annette Nesdale, Tony Dowell, Nikki Turner, Priscilla CampbellStokes et al., "Impact of the COVID-19 nonpharmaceutical interventions on influenza and other respiratory viral infections in New Zealand," Nature communications, 2021, 12 (1), $1-7$.

Isen, Adam, Maya Rossin-Slater, and Reed Walker, "Relationship between season of birth, temperature exposure, and later life wellbeing," Proceedings of the National Academy of Sciences, 2017, 114 (51), 13447-13452.

_ , _, and W Reed Walker, "Every breath you take - every dollar you'll make: The longterm consequences of the clean air act of 1970," Journal of Political Economy, 2017, 125 (3), 848-902.

Kelly, Elaine, "The scourge of asian flu in utero exposure to pandemic influenza and the development of a cohort of british children," Journal of Human resources, 2011, 46 (4), 669-694.

Kneyber, MCJ, EW Steyerberg, R De Groot, and HA Moll, "Long-term effects of respiratory syncytial virus (RSV) bronchiolitis in infants and young children: a quantitative review," Acta Paediatrica, 2000, 89 (6), 654-660.

Korppi, M, E Piippo-Savolainen, K Korhonen, and S Remes, "Respiratory morbidity 20 years after RSV infection in infancy," Pediatric pulmonology, 2004, 38 (2), 155-160.

Kuecken, Maria, Josselin Thuilliez, and Marie-Anne Valfort, "Disease and Human Capital Accumulation: Evidence from the Roll Back Malaria Partnership in Africa," The Economic Journal, 2021, 131 (637), 2171-2202. 
Kusel, Merci MH, Nicholas H de Klerk, Tatiana Kebadze, Vaike Vohma, Patrick G Holt, Sebastian L Johnston, and Peter D Sly, "Early-life respiratory viral infections, atopic sensitization, and risk of subsequent development of persistent asthma," Journal of Allergy and Clinical Immunology, 2007, 119 (5), 1105-1110.

Lehmann, Jee-Yeon K, Ana Nuevo-Chiquero, and Marian Vidal-Fernandez, "The early origins of birth order differences in children's outcomes and parental behavior," Journal of Human Resources, 2018, 53 (1), 123-156.

Leung, Nancy HL, Daniel KW Chu, Eunice YC Shiu, Kwok-Hung Chan, James J McDevitt, Benien JP Hau, Hui-Ling Yen, Yuguo Li, Dennis KM Ip, JS Malik Peiris et al., "Respiratory virus shedding in exhaled breath and efficacy of face masks," Nature medicine, 2020, 26 (5), 676-680.

Lin, Ming-Jen and Elaine M Liu, "Does in utero exposure to illness matter? The 1918 influenza epidemic in Taiwan as a natural experiment," Journal of health economics, 2014, 37, 152-163.

Lucas, Adrienne M, "Malaria eradication and educational attainment: evidence from Paraguay and Sri Lanka," American Economic Journal: Applied Economics, 2010, 2 (2), 46-71.

Lynge, Elsebeth, Jakob Lynge Sandegaard, and Matejka Rebolj, "The Danish national patient register," Scandinavian journal of public health, 2011, 39 (7_suppl), 30-33.

M'Rabet, Laura, Arjen Paul Vos, Gunther Boehm, and Johan Garssen, "Breastfeeding and its role in early development of the immune system in infants: consequences for health later in life," The Journal of nutrition, 2008, 138 (9), 1782S-1790S.

Pedersen, Carsten Bøcker, "The Danish civil registration system," Scandinavian journal of public health, 2011, 39 (7_suppl), 22-25.

Pei, Zhuan, Jörn-Steffen Pischke, and Hannes Schwandt, "Poorly measured confounders are more useful on the left than on the right," Journal of Business 85 Economic Statistics, 2019, 37 (2), 205-216.

Persson, Petra and Maya Rossin-Slater, "Family ruptures, stress, and the mental health of the next generation," American economic review, 2018, 108 (4-5), 1214-52.

Petersson, Flemming, Mikkel Baadsgaard, and Lau Caspar Thygesen, "Danish registers on personal labour market affiliation," Scandinavian journal of public health, 2011, 39 (7_suppl), 95-98.

Pichler, Stefan and Nicolas R Ziebarth, "Labor market effects of US sick pay mandates," Journal of Human Resources, 2020, 55 (2), 611-659.

Pitzer, Virginia E, Cécile Viboud, Wladimir J Alonso, Tanya Wilcox, C Jessica Metcalf, Claudia A Steiner, Amber K Haynes, and Bryan T Grenfell, "Environmental drivers of the spatiotemporal dynamics of respiratory syncytial virus in the United States," PLoS pathogens, 2015, 11 (1), e1004591. 
Price, Joseph, "Parent-child quality time does birth order matter?," Journal of human resources, 2008, 43 (1), 240-265.

Pruckner, Gerald J., Nicole Schneeweis, Thomas Schober, and Martina Zweimüller, "Birth order, parental health investment, and health in childhood," Journal of Health Economics, 2021, 76, 102426.

Rasmussen, Astrid Würtz, "Increasing the length of parents' birth-related leave: The effect on children's long-term educational outcomes," Labour Economics, 2010, 17 (1), 91-100.

Régnier, Stéphane A and Jasper Huels, "Association between respiratory syncytial virus hospitalizations in infants and respiratory sequelae: systematic review and meta-analysis," The Pediatric infectious disease journal, 2013, 32 (8), 820-826.

Rha, Brian, Aaron T Curns, Joana Y Lively, Angela P Campbell, Janet A Englund, Julie A Boom, Parvin H Azimi, Geoffrey A Weinberg, Mary A Staat, Rangaraj Selvarangan et al., "Respiratory syncytial virus-associated hospitalizations among young children: 2015-2016," Pediatrics, 2020, 146 (1).

Schwandt, Hannes, "The lasting legacy of seasonal influenza: In-utero exposure and labor market outcomes," CEPR Discussion Paper, 2018.

Venkataramani, Atheendar S, "Early life exposure to malaria and cognition in adulthood: evidence from Mexico," Journal of health economics, 2012, 31 (5), 767-780.

White, Corey, "Measuring social and externality benefits of influenza vaccination," Journal of Human Resources, 2019, pp. 1118-9893R2.

Yi, Junjian, James J Heckman, Junsen Zhang, and Gabriella Conti, "Early health shocks, intra-household resource allocation and child outcomes," The Economic Journal, 2015, 125 (588), F347-F371.

Zomer-Kooijker, Kim, Cornelis K van der Ent, Marieke JJ Ermers, Cuno SPM Uiterwaal, Maroeska M Rovers, Louis J Bont, and RSV Corticosteroid Study Group, "Increased risk of wheeze and decreased lung function after respiratory syncytial virus infection," PloS one, 2014, 9 (1), e87162. 


\section{$6 \quad$ Figures}

Figure 1: Number of Respiratory Hospitalizations per 100 Children, by Child Age in Months, Older versus Younger Siblings

(a) During First Year of Life

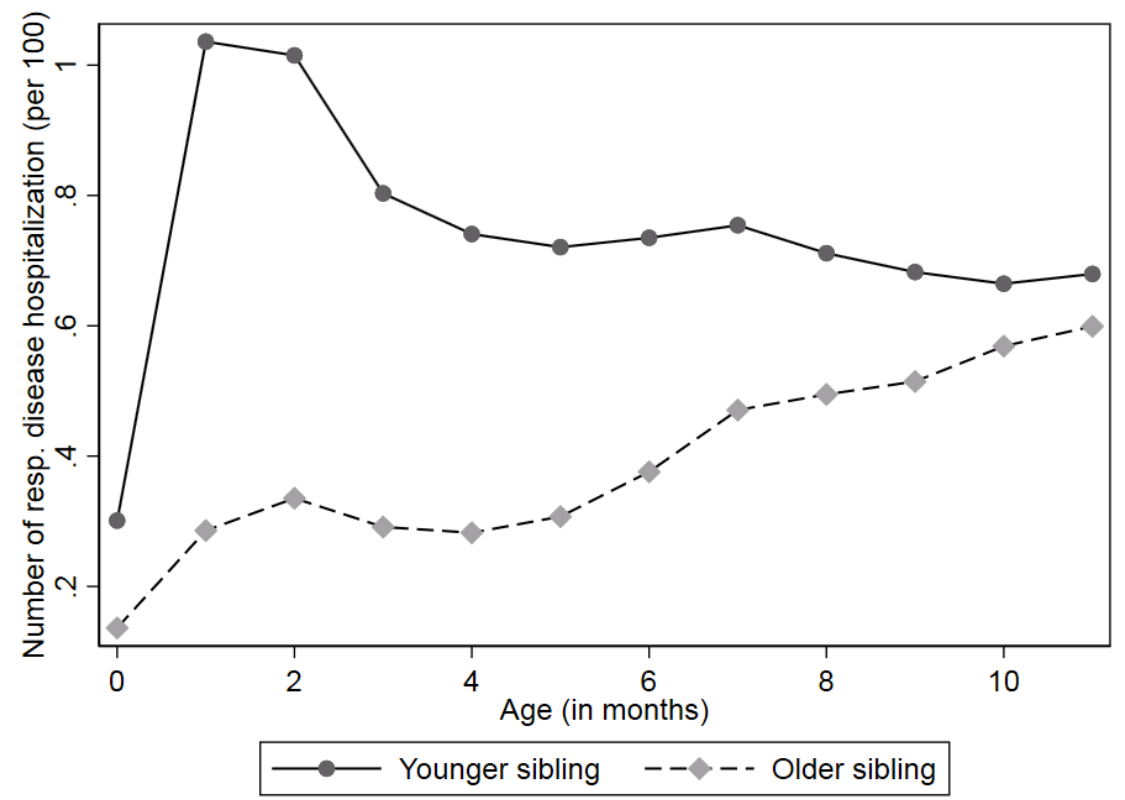

(b) During First Five Years of Life

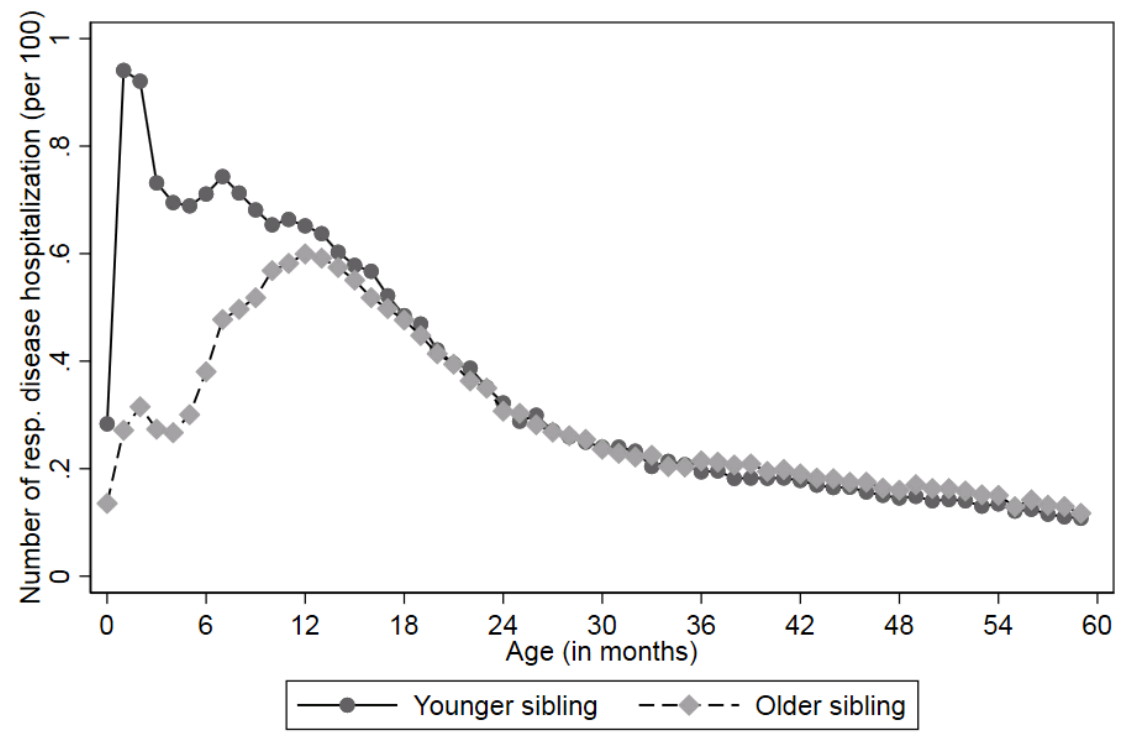

Notes: These figures plot the number of hospitalizations with respiratory illness diagnoses (per 100 children) by month of age, separately for older and younger siblings in our data. 
Figure 2: Number of Respiratory Hospitalizations per 100 Children, by Child Age in Months and Season of Birth, Older versus Younger Siblings
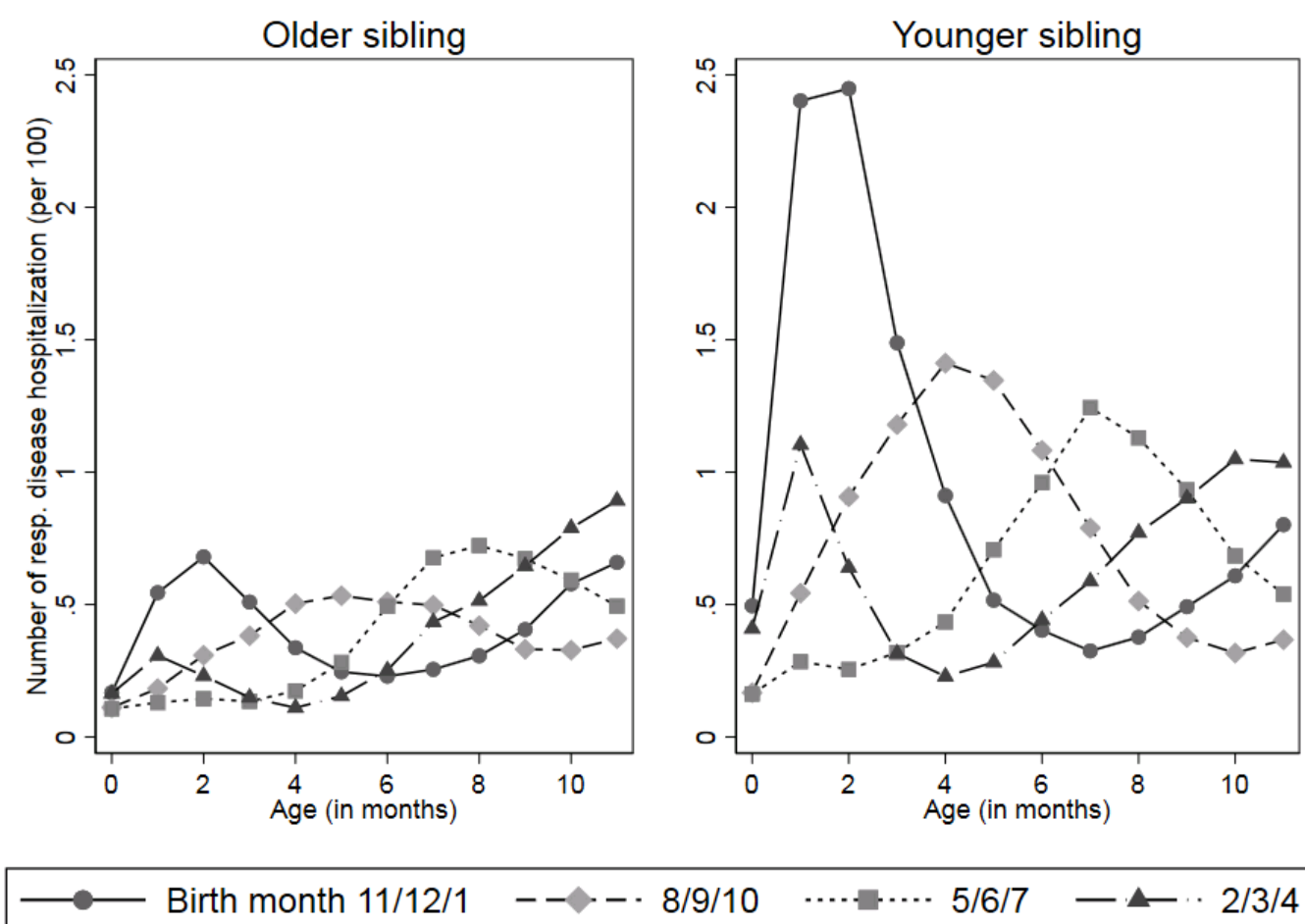

Notes: These figures plot the number of hospitalizations with respiratory illness diagnoses (per 100 children) by month of age and by the season of birth of the child, separately for older and younger siblings in our data. 
Figure 3: Number of Respiratory Hospitalizations per 100 Children, by Child Age in Months, Season of Birth, and Birth Spacing, Older versus Younger Siblings

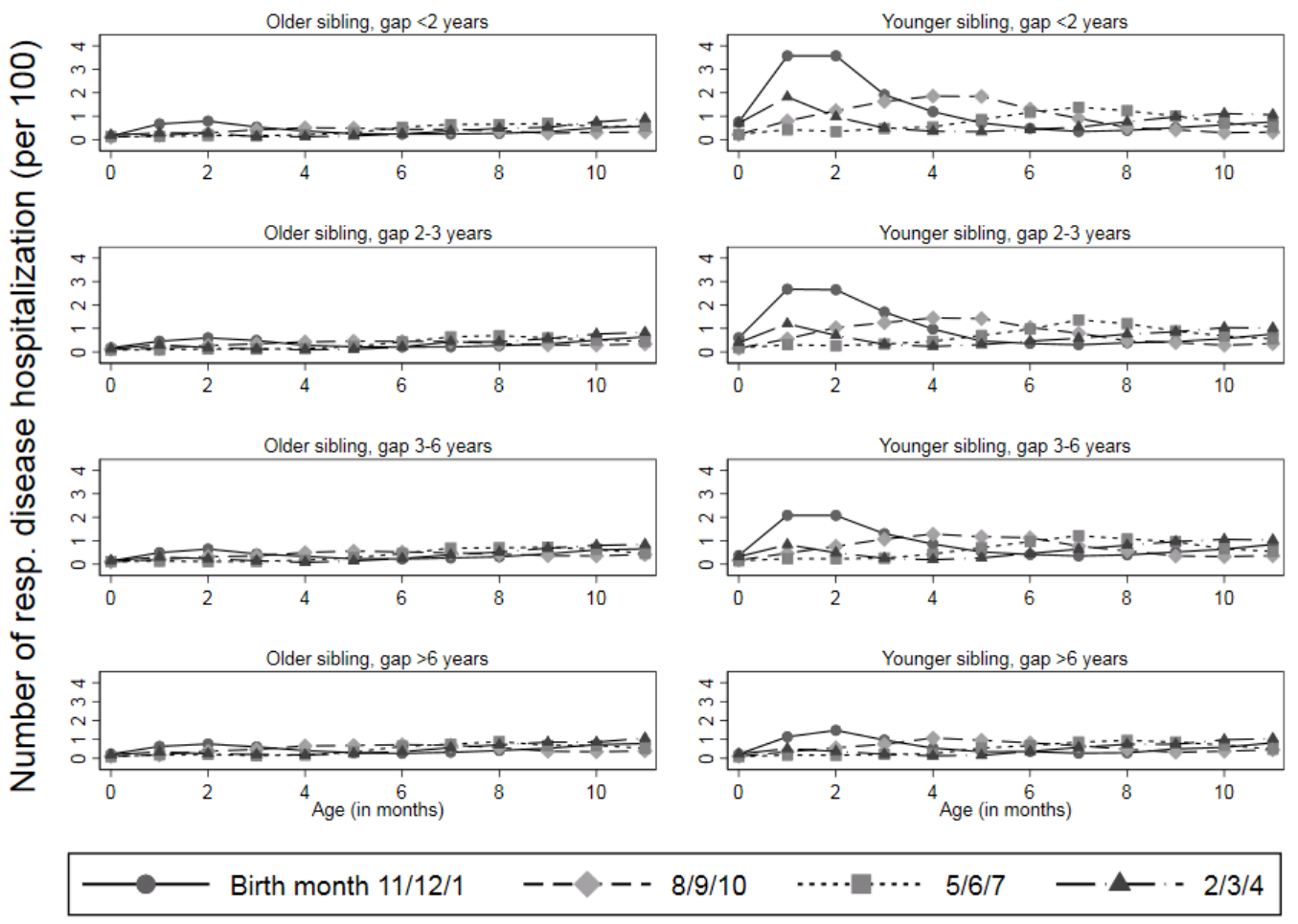

Notes: These figures plot the number of hospitalizations with respiratory illness diagnoses (per 100 children) by month of age and by the season of birth of the child, separately for older and younger siblings with different birth spacing gaps in our data. 
Figure 4: Differential Effects of the Respiratory Disease Exposure Index on the Annual Number of Younger Siblings' Respiratory and RSV Hospitalizations, by Age of Observation and by Sub-Group

(a) By Age of Observation, All Resp.

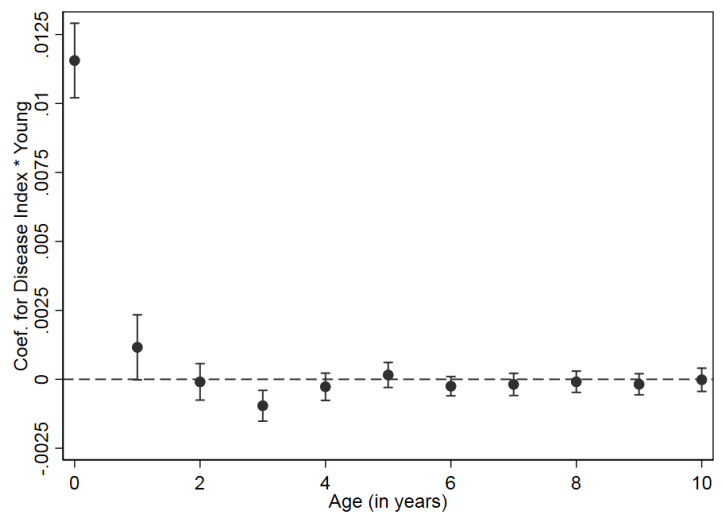

(c) By Sub-Group, All Resp.

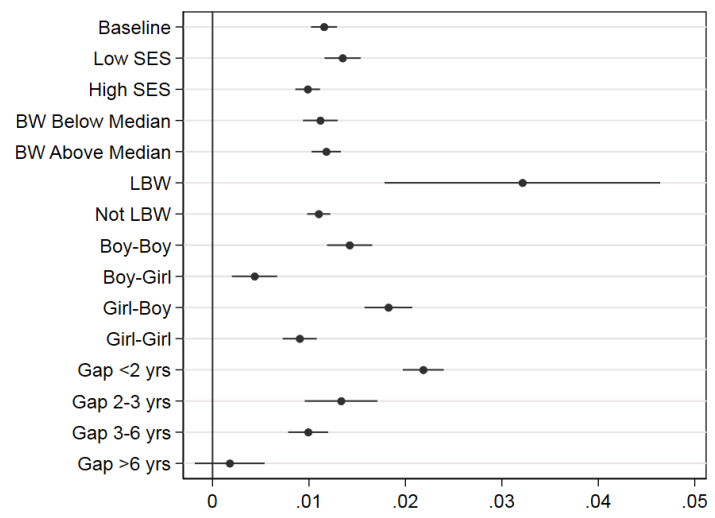

(b) By Age of Observation, RSV

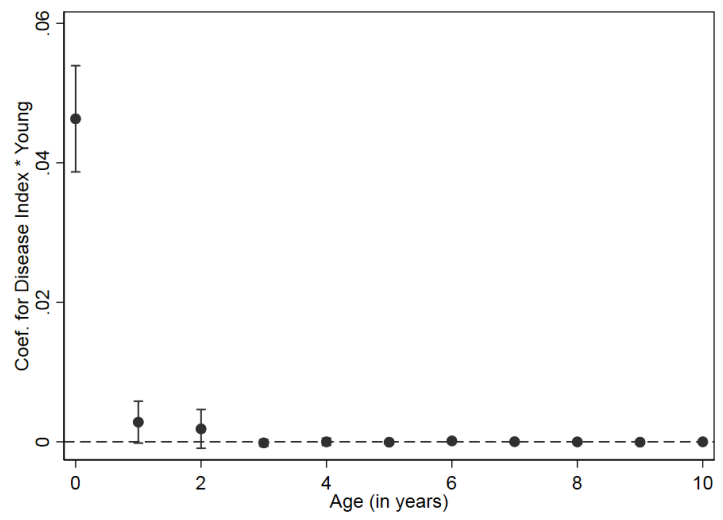

(d) By Sub-Group, RSV

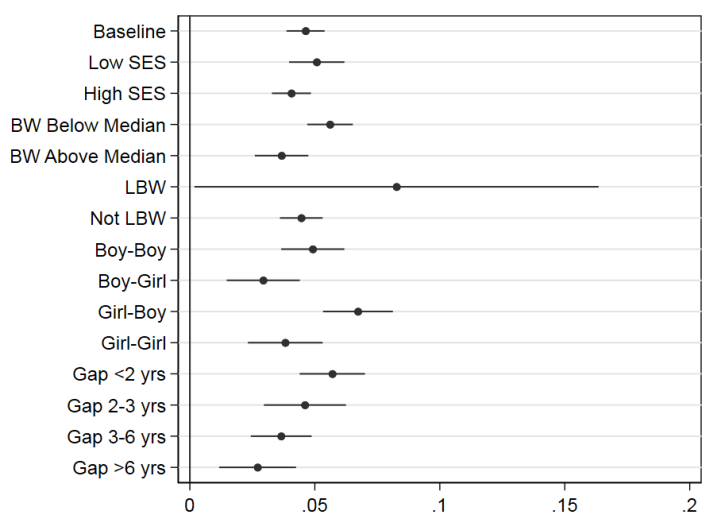

Notes: Sub-figures (a) and (b) plot the coefficients and 95\% confidence intervals on the interaction term between the disease index and the younger sibling indicator from model (1), using as outcomes the annual number of hospitalizations with all respiratory diagnoses and RSV diagnoses, respectively, measured at ages specified on the x-axis. Sub-figures (c) and (d) plot these coefficients and 95\% confidence intervals for these two outcomes measured in the first year of life, from models estimated on different sub-samples as specified on the y-axis. 
Figure 5: Differential Effects of the Respiratory Disease Exposure Index on Younger Siblings' Long-Run Outcomes, by Age of Observation

(a) High School Graduation

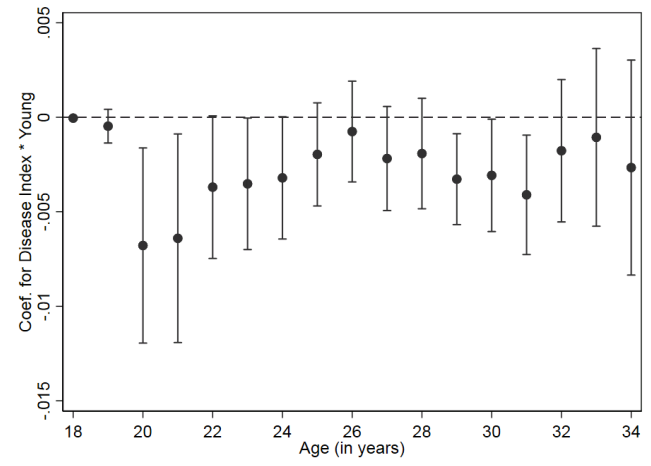

(c) Labor Force Participation

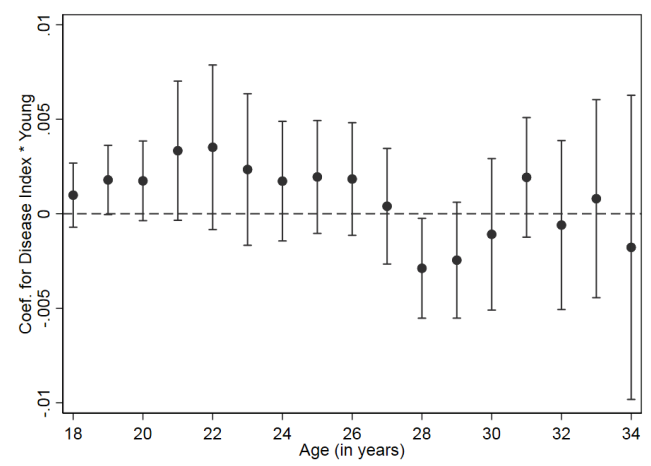

(b) College Graduation

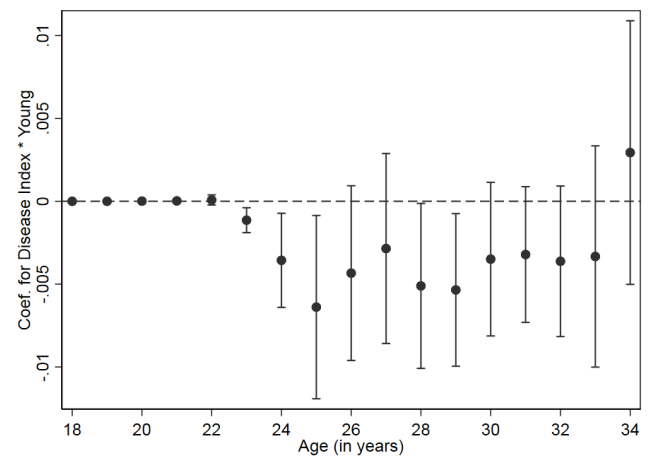

(d) Income

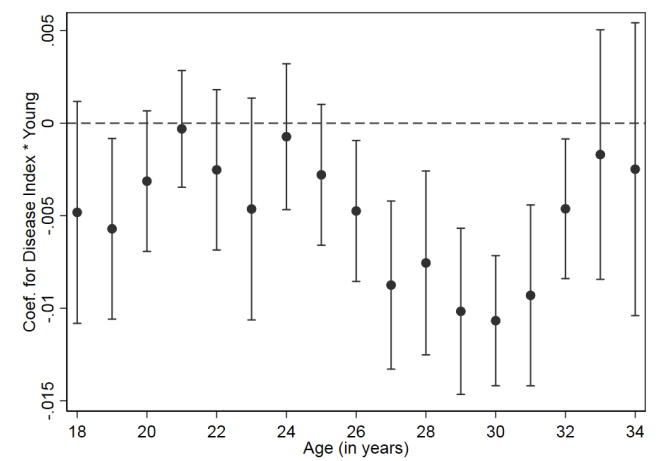

Notes: These figures plot the coefficients and $95 \%$ confidence intervals on the interaction term between the disease index and the younger sibling indicator from model (1), using outcomes measured at ages specified on the x-axes. 


\section{Tables}

Table 1: Variable Means

\begin{tabular}{lcc}
\hline & Older Siblings & Younger Siblings \\
\hline Child Characteristics and Outcomes & & \\
\hline Male Child & 0.514 & 0.514 \\
Birth Weight (grams) & 3430.702 & 3588.422 \\
Respiratory Disease Exposure Index & 2.795 & 2.877 \\
Number of Respiratory Disease Hospitalizations by Age 1 & 0.047 & 0.090 \\
RSV Exposure Index & 0.107 & 0.102 \\
Number of RSV Hospitalizations by Age 1 & 0.009 & 0.027 \\
Log Income, Age 30 & 10.805 & 10.766 \\
Log Wage, Age 30 & 10.681 & 10.639 \\
Log Income (conditional on employed), Age 30 & 11.035 & 11.004 \\
Log Wage (conditional on employed), Age 30 & 10.917 & 10.888 \\
In Labor Force, Age 30 & 0.805 & 0.799 \\
Employed, Age 30 & 0.786 & 0.780 \\
High School Degree, Age 30 & 0.849 & 0.840 \\
College Degree, Age 30 & 0.447 & 0.427 \\
Danish Test Score, Grade 9 & 0.152 & 0.048 \\
Math Test Score, Grade 9 & 0.207 & 0.077 \\
\hline Family Background Characteristics & & \\
\hline Mother's Age at Childbirth & 26.824 & 30.323 \\
Mother is Foreign-Born & 0.045 & 0.045 \\
Mother has High School Degree & 0.751 & 0.789 \\
Mother has College Degree & 0.302 & 0.368 \\
Parents are Married/Cohabiting & 0.822 & 0.938 \\
Log Household Income & 11.424 & 11.600 \\
\hline Observations & 588,373 & 588,373 \\
\hline Notes: The & & \\
\hline
\end{tabular}

Notes: This table presents the means of key variables in our analysis separately for older and younger siblings. The respiratory disease exposure index is the number of inpatient admissions with a respiratory disease primary diagnosis among children aged 13-71 months per 100 children in the focal child's municipality of birth during the first year of life, excluding any hospitalizations of an older sibling. Income variables are reported in 2010 \$USD. Test scores are converted into $z$-scores, which are standardized within each subject and test year. Test score data are only available for children born in 1986-2003. Maternal educational attainment and parental marital/cohabiting status are measured in the year of childbirth, while household income is measured in the year before childbirth. 
Table 2: Effect of Respiratory Disease Exposure Index on Respiratory Disease Hospitalizations in First Year of Life, Younger versus Older Siblings

\begin{tabular}{|c|c|c|c|c|c|}
\hline & 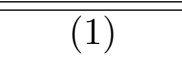 & 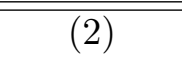 & 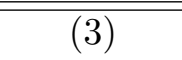 & 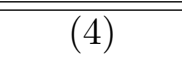 & 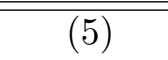 \\
\hline \multicolumn{6}{|c|}{ A. All Respiratory Disease Hospitalizations in First Year of Life } \\
\hline Younger & $\begin{array}{c}0.039^{* * *} \\
(0.002)\end{array}$ & & $\begin{array}{c}0.039^{* * *} \\
(0.002)\end{array}$ & $\begin{array}{c}0.006^{* * *} \\
(0.002)\end{array}$ & $\begin{array}{c}0.017^{* * *} \\
(0.002)\end{array}$ \\
\hline Disease index & & $\begin{array}{c}0.017^{* * *} \\
(0.001)\end{array}$ & $\begin{array}{c}0.017^{* * *} \\
(0.001)\end{array}$ & $\begin{array}{c}0.010^{* * *} \\
(0.001)\end{array}$ & $\begin{array}{c}0.010^{* * *} \\
(0.001)\end{array}$ \\
\hline Younger $\mathrm{x}$ disease index & & & & $\begin{array}{c}0.011^{* * *} \\
(0.001)\end{array}$ & $\begin{array}{c}0.012^{\text {*** }} \\
(0.001)\end{array}$ \\
\hline Observations & $1,176,746$ & $1,176,746$ & $1,176,746$ & $1,176,746$ & $1,176,746$ \\
\hline Mean & 0.068 & 0.068 & 0.068 & 0.068 & 0.068 \\
\hline 25 th to 75 th pctile effect size & & & & 0.021 & 0.021 \\
\hline \multicolumn{6}{|c|}{ B. RSV Hospitalizations in First Year of Life } \\
\hline Younger & $\begin{array}{c}0.018^{* * *} \\
(0.001)\end{array}$ & & $\begin{array}{c}0.018^{* * *} \\
(0.001)\end{array}$ & $\begin{array}{c}0.013^{* * *} \\
(0.001)\end{array}$ & $\begin{array}{c}0.016^{* * *} \\
(0.001)\end{array}$ \\
\hline Disease index & & $\begin{array}{c}0.040^{* * *} \\
(0.004)\end{array}$ & $\begin{array}{c}0.040^{* * *} \\
(0.004)\end{array}$ & $\begin{array}{c}0.016^{* * *} \\
(0.003)\end{array}$ & $\begin{array}{c}0.016^{* * *} \\
(0.003)\end{array}$ \\
\hline Younger $\mathrm{x}$ disease index & & & & $\begin{array}{c}0.046^{* * *} \\
(0.004)\end{array}$ & $\begin{array}{c}0.046^{* * *} \\
(0.004)\end{array}$ \\
\hline Observations & 697,128 & 697,128 & 697,128 & 697,128 & 697,128 \\
\hline Mean & 0.018 & 0.018 & 0.018 & 0.018 & 0.018 \\
\hline 25 th to 75 th pctile effect size & & & & 0.005 & 0.005 \\
\hline Municipality FEs & Yes & Yes & Yes & Yes & Yes \\
\hline YoB+MoB FEs & Yes & Yes & Yes & Yes & Yes \\
\hline Family Background Controls & No & No & No & No & Yes \\
\hline
\end{tabular}

Notes: Each column in each panel in the table presents results from estimating different versions of model (1). In Panel A, the outcome is the number of hospitalizations with any respiratory disease primary diagnosis during the first year of the child's life. In Panel B, the outcome is the number of hospitalizations with an RSV primary diagnosis during the first year of the child's life. We report the coefficients on the indicator variable denoting the younger sibling ("Younger"), the respiratory disease exposure index ("Disease index"), and the interaction of these two variables. The respiratory disease exposure index is the number of inpatient admissions with any respiratory disease primary diagnosis among children aged 13-71 months per 100 children in each child's municipality of birth during the first year of life, excluding any hospitalizations of an older sibling. All specifications include municipality, year of birth, and month of birth fixed effects. Column (5) also includes the following family background controls: indicator for child gender, mother's age and age squared, indicator for the mother being foreign-born, indicators for mother's education level (high school degree, college degree or higher), and an indicator for the parents being married or cohabiting at the time of childbirth. Standard errors are clustered on the child's municipality of birth in all models. The "25th to 75 th pctile effect size" row reports the magnitude of the differential effect of an increase in the disease exposure index from the 25 th to the 75 th percentile of the distribution for younger siblings. Significance levels: ${ }^{*} \mathrm{p}<0.1 * * \mathrm{p}<0.05^{* * *} \mathrm{p}<0.01$. 
Table 3: Effect of Respiratory Disease Exposure Index in First Year of Life on Likelihood of High School Graduation, Younger versus Older Siblings

\begin{tabular}{lcccc}
\hline \hline & \multicolumn{3}{c}{ Graduated High School by Age 30 } \\
\cline { 2 - 5 } & $(1)$ & $(2)$ & $(3)$ & $(4)$ \\
\hline Younger & $-0.051^{* * *}$ & & $-0.051^{* * *}$ & $-0.044^{* * *}$ \\
Disease index & $(0.003)$ & & $(0.003)$ & $(0.004)$ \\
& & 0.003 & 0.003 & $0.006^{* *}$ \\
Younger x disease index & & $(0.003)$ & $(0.003)$ & $(0.003)$ \\
& & & & $-0.003^{* *}$ \\
Municipality FEs & Yes & Yes & Yes & $(0.001)$ \\
YoB+MoB FEs & Yes & Yes & Yes & Yes \\
Family Background Controls & Yes & Yes & Yes & Yes \\
\hline Observations & 148,876 & 148,876 & 148,876 & 148,876 \\
Mean & 0.844 & 0.844 & 0.844 & 0.844 \\
25th to 75th pctile effect size & & & & -0.004 \\
\hline \hline
\end{tabular}

Notes: See notes under Table 2 for more details about the specifications and variables. The outcome is an indicator for graduating high school by age 30 . Standard errors are clustered on the child's municipality of birth. Significance levels: ${ }^{*} \mathrm{p}<0.1$ $* * \mathrm{p}<0.05^{* * *} \mathrm{p}<0.01$.

Table 4: Effect of Respiratory Disease Exposure Index in First Year of Life on Likelihood of College Graduation, Younger versus Older Siblings

\begin{tabular}{lcccc}
\hline \hline & \multicolumn{3}{c}{ Graduated College by Age 30 } \\
\cline { 2 - 5 } & $(1)$ & $(2)$ & $(3)$ & $(4)$ \\
\hline Younger & $-0.090^{* * *}$ & & $-0.090^{* * *}$ & $-0.082^{* * *}$ \\
Disease index & $(0.004)$ & & $(0.004)$ & $(0.006)$ \\
& & -0.001 & -0.000 & 0.002 \\
Younger x disease index & & $(0.003)$ & $(0.003)$ & $(0.003)$ \\
& & & & -0.003 \\
Municipality FEs & Yes & Yes & Yes & $(0.002)$ \\
YoB+MoB FEs & Yes & Yes & Yes & Yes \\
Family Background Controls & Yes & Yes & Yes & Yes \\
\hline Observations & 148,876 & 148,876 & 148,876 & 148,876 \\
Mean & 0.437 & 0.437 & 0.437 & 0.437 \\
25th to 75th pctile effect size & & & & -0.004 \\
\hline \hline
\end{tabular}

Notes: See notes under Table 2 for more details about the specifications and variables. The outcome is an indicator for graduating college by age 30. Standard errors are clustered on the child's municipality of birth. Significance levels: ${ }^{*} \mathrm{p}<0.1$ ** $\mathrm{p}<0.05^{* * *} \mathrm{p}<0.01$. 
Table 5: Effect of Respiratory Disease Exposure Index in First Year of Life on Labor Force Participation at Age 30, Younger versus Older Siblings

\begin{tabular}{lcccc}
\hline \hline & \multicolumn{3}{c}{ Labor Force Participation at Age 30 } \\
\cline { 2 - 5 } & $(1)$ & $(2)$ & $(3)$ & $(4)$ \\
\hline Younger & $-0.018^{* * *}$ & & $-0.018^{* * *}$ & $-0.016^{* * *}$ \\
Disease index & $(0.003)$ & & $(0.003)$ & $(0.006)$ \\
& & -0.000 & -0.000 & 0.000 \\
Younger x disease index & & $(0.003)$ & $(0.003)$ & $(0.003)$ \\
& & & & -0.001 \\
Municipality FEs & Yes & Yes & Yes & $(0.002)$ \\
YoB+MoB FEs & Yes & Yes & Yes & Yes \\
Family Background Controls & Yes & Yes & Yes & Yes \\
\hline Observations & 165,736 & 165,736 & 165,736 & 165,736 \\
Mean & 0.802 & 0.802 & 0.802 & 0.802 \\
25th to 75th pctile effect size & & & & -0.001 \\
\hline \hline
\end{tabular}

Notes: See notes under Table 2 for more details about the specifications and variables. The outcome is an indicator for being in the labor force at age 30. Standard errors are clustered on the child's municipality of birth. Significance levels: ${ }^{*} \mathrm{p}<0.1$ $* * \mathrm{p}<0.05^{* * *} \mathrm{p}<0.01$.

Table 6: Effect of Respiratory Disease Exposure Index in First Year of Life on Log Income (Conditional on Employed) at Age 30, Younger versus Older Siblings

\begin{tabular}{lcccc}
\hline \hline & \multicolumn{3}{c}{ Log Income at Age 30 } \\
\cline { 2 - 5 } & $(1)$ & $(2)$ & $(3)$ & $(4)$ \\
\hline Younger & $-0.028^{* * *}$ & & $-0.028^{* * *}$ & -0.005 \\
Disease index & $(0.003)$ & & $(0.003)$ & $(0.005)$ \\
& & $-0.006^{* *}$ & $-0.006^{* *}$ & 0.002 \\
Younger x disease index & & $(0.003)$ & $(0.003)$ & $(0.003)$ \\
& & & & $-0.011^{* * *}$ \\
Municipality FEs & Yes & Yes & Yes & Yes \\
YoB+MoB FEs & Yes & Yes & Yes & Yes \\
Family Background Controls & Yes & Yes & Yes & Yes \\
\hline Observations & 104,806 & 104,806 & 104,806 & 104,806 \\
Mean & 11.019 & 11.019 & 11.019 & 11.019 \\
25th to 75th pctile effect size & & & & -0.013 \\
\hline \hline
\end{tabular}

Notes: See notes under Table 2 for more details about the specifications and variables. The outcome is the natural log of gross income (conditional on employed) at age 30, converted into 2010 USD $\$$. Standard errors are clustered on the child's municipality of birth. Significance levels: ${ }^{*} \mathrm{p}<0.1 * * \mathrm{p}<0.05^{* * *} \mathrm{p}<0.01$. 


\section{A Appendix Figures}

Figure A1: Variation in the Respiratory Disease Index Over Time, 15 Largest Municipalities

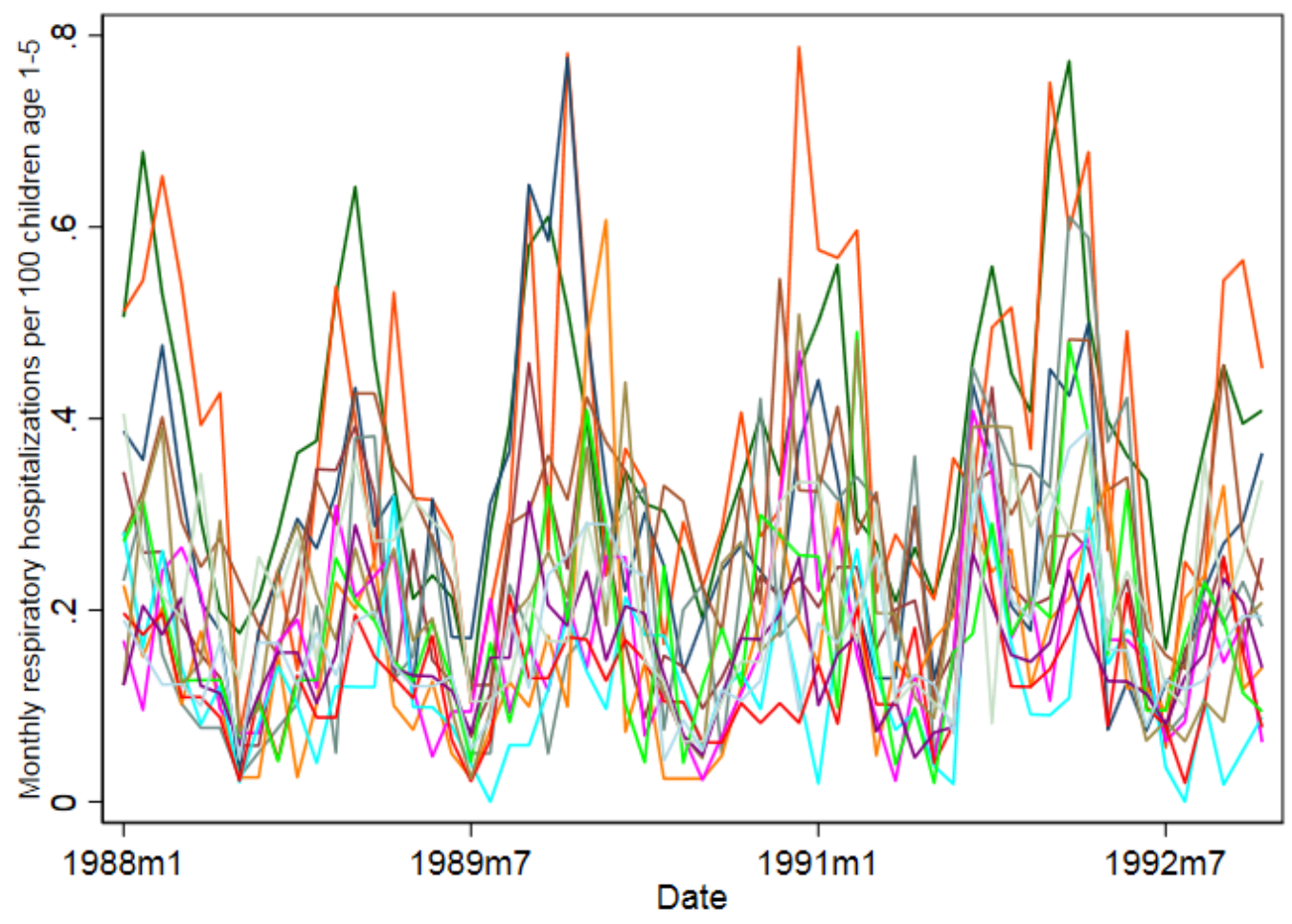

Notes: This figure shows the monthly variation in the respiratory disease index over time for each of the 15 largest municipalities (in terms of population size) in Denmark. The respiratory disease index refers to the number of respiratory disease hospitalizations per 100 children aged 13 to 71 months in each calendar year-month. 
Figure A2: Distribution of Respiratory Disease Index Residuals from Municipality and YearMonth Fixed Effects

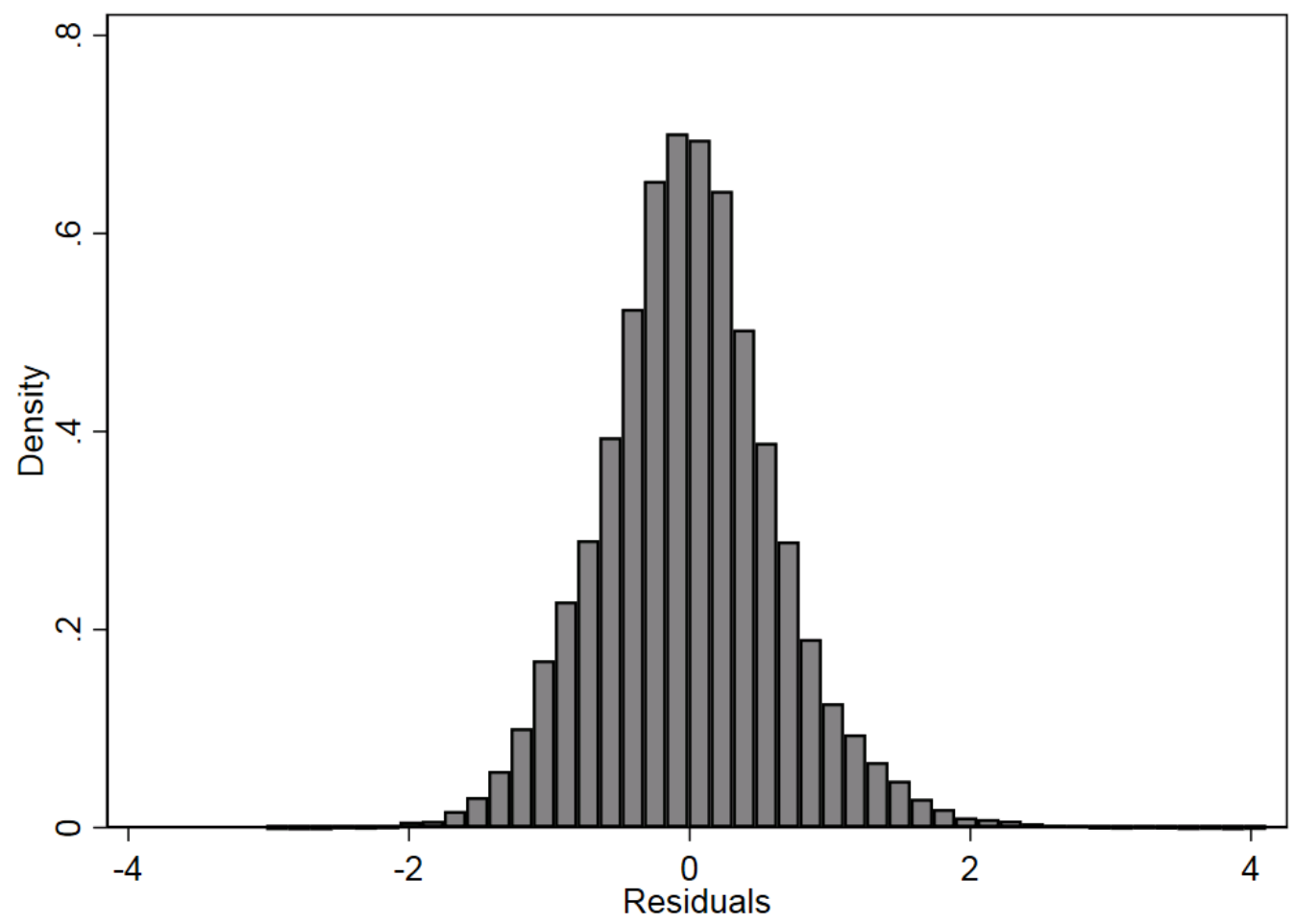

Notes: This histogram plots the residuals after regressing the respiratory disease index on municipality and year-month fixed effects. The respiratory disease index refers to the number of respiratory disease hospitalizations per 100 children aged 13 to 71 months in each calendar year-month. 


\section{B Appendix Tables}

Table A1: Disease Exposure Index and Family Background Characteristics

\begin{tabular}{|c|c|c|c|c|c|c|c|c|c|c|c|}
\hline & $\begin{array}{c}(1) \\
\text { Male }\end{array}$ & $\begin{array}{c}(2) \\
\text { Mother's } \\
\text { Age }\end{array}$ & $\begin{array}{c}(3) \\
\text { Mother } \\
\text { Foreign-Born }\end{array}$ & $\begin{array}{c}(4) \\
\text { Mother HS } \\
\text { Graduated }\end{array}$ & $\begin{array}{c}(5) \\
\text { Mother College } \\
\text { Graduated }\end{array}$ & $\begin{array}{c}(6) \\
\text { Parents Married/ } \\
\text { Cohabiting }\end{array}$ & $\begin{array}{c}(7) \\
\text { Father } \\
\text { Log Income }\end{array}$ & $\begin{array}{c}(8) \\
\text { Mother } \\
\text { Log Income }\end{array}$ & $\begin{array}{c}(9) \\
\text { Household } \\
\text { Log Income }\end{array}$ & $\begin{array}{c}(10) \\
\text { Father } \\
\text { Employed }\end{array}$ & $\begin{array}{c}(11) \\
\text { Mother } \\
\text { Employed }\end{array}$ \\
\hline Younger & $\begin{array}{l}-.00215 \\
(.0029)\end{array}$ & $\begin{array}{l}2.78^{* * *} \\
(.0509)\end{array}$ & $\begin{array}{l}-.00703^{*} \\
(.00407)\end{array}$ & $\begin{array}{c}.01 \\
(.00896)\end{array}$ & $\begin{array}{l}.0417^{* * *} \\
(.00494)\end{array}$ & $\begin{array}{l}.102^{* * *} \\
(.00541)\end{array}$ & $\begin{array}{l}.135^{* * *} \\
(.026)\end{array}$ & $\begin{array}{l}.166^{* * *} \\
(.0178)\end{array}$ & $\begin{array}{l}.133^{* * *} \\
(.0196)\end{array}$ & $\begin{array}{l}.0523^{* * *} \\
(.0147)\end{array}$ & $\begin{array}{c}.0165 \\
(.0153)\end{array}$ \\
\hline Disease index & $\begin{array}{c}-.00107 \\
(.000794)\end{array}$ & $\begin{array}{c}-.138^{* * *} \\
(.0337)\end{array}$ & $\begin{array}{r}-.000119 \\
(.00149)\end{array}$ & $\begin{array}{l}.00314 \\
(.0021)\end{array}$ & $\begin{array}{c}-.0151^{* *} \\
(.00609)\end{array}$ & $\begin{array}{c}-.00717^{* * *} \\
(.00267)\end{array}$ & $\begin{array}{l}-.014^{* * *} \\
(.00405)\end{array}$ & $\begin{array}{c}-.00876^{* * *} \\
(.00311)\end{array}$ & $\begin{array}{c}-.0122^{* * *} \\
(.00365)\end{array}$ & $\begin{array}{c}-.00671^{* * *} \\
(.00239)\end{array}$ & $\begin{array}{l}-.00107 \\
(.00278)\end{array}$ \\
\hline Younger $\mathrm{x}$ disease index & $\begin{array}{l}.000442 \\
(.000961)\end{array}$ & $\begin{array}{l}.109^{* * *} \\
(.0325)\end{array}$ & $\begin{array}{c}.000933 \\
(.002)\end{array}$ & $\begin{array}{l}-.00176 \\
(.0041)\end{array}$ & $\begin{array}{c}.00072 \\
(.00119)\end{array}$ & $\begin{array}{c}.00115 \\
(.00197)\end{array}$ & $\begin{array}{l}.00486 \\
(.00674)\end{array}$ & $\begin{array}{c}.00267 \\
(.00575)\end{array}$ & $\begin{array}{l}.00324 \\
(.0052)\end{array}$ & $\begin{array}{l}-.00198 \\
(.00381)\end{array}$ & $\begin{array}{l}-.00179 \\
(.00396)\end{array}$ \\
\hline
\end{tabular}

Notes: Each column in the table presents results from estimating model (1), separately for each of the dependent variables listed at the top. We report the coefficients on the indicator variable denoting the younger sibling ("Younger"), the respiratory disease exposure index ("Disease index"), and the interaction of these two variables. The disease exposure index is the number of inpatient admissions with a respiratory disease primary diagnosis among children aged 13-71 months per 100 children in each child's municipality of birth during the first year of life, excluding any hospitalizations of an older sibling. See notes under Table 2 for more details about the specifications. Standard errors are clustered on the child's municipality of birth in all models. Significance levels: $* \mathrm{p}<0.1 * * \mathrm{p}<0.05 * * *$ $\mathrm{p}<0.01$. 
Table A2: Effect of Non-Infectious Digestive Disease Exposure Index on Non-Infectious Digestive Disease Hospitalizations in First Year of Life, Younger versus Older Siblings

\begin{tabular}{|c|c|c|c|c|c|}
\hline & \multicolumn{5}{|c|}{ Non-infectious Digestive Disease Hospitalizations in First Year of Life $\left({ }^{*} 1000\right)$} \\
\hline & $(1)$ & $(2)$ & $(3)$ & $(4)$ & $(5)$ \\
\hline Younger & $\begin{array}{c}-0.392^{* * *} \\
(0.146)\end{array}$ & & $\begin{array}{c}-0.397^{* * *} \\
(0.150)\end{array}$ & $\begin{array}{c}-0.521^{* *} \\
(0.242)\end{array}$ & $\begin{array}{c}-0.425^{*} \\
(0.233)\end{array}$ \\
\hline Non-infectious disease index & & $\begin{array}{c}5.138^{* * *} \\
(1.559)\end{array}$ & $\begin{array}{c}5.149^{* * *} \\
(1.569)\end{array}$ & $\begin{array}{c}4.527^{* * *} \\
(1.589)\end{array}$ & $\begin{array}{c}4.511^{* * *} \\
(1.591)\end{array}$ \\
\hline Younger x Non-infectious disease index & & & & $\begin{array}{c}1.014 \\
(1.341)\end{array}$ & $\begin{array}{c}1.049 \\
(1.348)\end{array}$ \\
\hline Municipality FEs & Yes & Yes & Yes & Yes & Yes \\
\hline $\mathrm{YoB}+\mathrm{MoB}$ FEs & Yes & Yes & Yes & Yes & Yes \\
\hline Family Background Controls & No & No & No & No & Yes \\
\hline Observations & 697,128 & 697,128 & 697,128 & 697,128 & 697,128 \\
\hline Mean & 2.275 & 2.275 & 2.275 & 2.275 & 2.275 \\
\hline 25 th to 75 th pctile effect size & & & & 0.109 & 0.113 \\
\hline
\end{tabular}

Notes: Each column in each panel in the table presents results from estimating different versions of model (1), with a disease index based on non-infectious digestive disease hospitalizations instead of respiratory disease hospitalizations. The outcome is the number of hospitalizations with any non-infectious digestive disease primary diagnosis during the first year of the child's life. We report the coefficients on the indicator variable denoting the younger sibling ("Younger"), the non-infectious disease exposure index ("Non-infectious disease index"), and the interaction of these two variables. The non-infectious disease exposure index is the number of inpatient admissions with any non-infectious digestive disease primary diagnosis among children aged 13-71 months per 100 children in each child's municipality of birth during the first year of life, excluding any hospitalizations of an older sibling. All specifications include municipality, year of birth, and month of birth fixed effects. Column (5) also includes the following family background controls: indicator for child gender, mother's age and age squared, indicator for the mother being foreign-born, indicators for mother's education level (high school degree, college degree or higher), and an indicator for the parents being married or cohabiting at the time of childbirth. Standard errors are clustered on the child's municipality of birth in all models. The "25th to 75 th pctile effect size" row reports the magnitude of the differential effect of an increase in the disease exposure index from the 25th to the 75th percentile of the distribution for younger siblings. Significance levels: $* \mathrm{p}<0.1 * * \mathrm{p}<0.05 * * * \mathrm{p}<0.01$. 
Table A3: Effect of Injury (incl. Poisoning) Exposure Index on Injury (incl. Poisoning) Hospitalizations in First Year of Life, Younger versus Older Siblings

\begin{tabular}{lccccc}
\hline \hline & \multicolumn{4}{l}{ Injury (incl. Poisonings) Hospitalizations in First Year of Life $\left(^{*} 1000\right)$} \\
\cline { 2 - 6 } & $(1)$ & $(2)$ & $(3)$ & $(4)$ & $(5)$ \\
\hline Younger & $-2.427^{* * *}$ & & $-2.461^{* * *}$ & 1.667 & $8.454^{* * *}$ \\
& $(0.842)$ & & $(0.854)$ & $(2.120)$ & $(2.396)$ \\
Injury index & & $2.288^{* * *}$ & $2.289^{* * *}$ & $2.387^{* * *}$ & $2.320^{* * *}$ \\
& & $(0.188)$ & $(0.188)$ & $(0.210)$ & $(0.205)$ \\
Younger x injury index & & & & $-0.238^{*}$ & $-0.248^{*}$ \\
& & & & $(0.134)$ & $(0.141)$ \\
Municipality FEs & Yes & Yes & Yes & Yes & Yes \\
YoB+MoB FEs & Yes & Yes & Yes & Yes & Yes \\
Family Background Controls & No & No & No & No & Yes \\
\hline Observations & 697,128 & 697,128 & 697,128 & 697,128 & 697,128 \\
Mean & 50.965 & 50.965 & 50.965 & 50.965 & 50.965 \\
25th to 75th pctile effect size & & & & -1.607 & -1.678 \\
\hline \hline
\end{tabular}

Notes: Each column in each panel in the table presents results from estimating different versions of model (1), with an index based on injury (incl. poisoning) hospitalizations instead of respiratory disease hospitalizations. The outcome is the number of hospitalizations with any injury (incl. poisoning) primary diagnosis during the first year of the child's life. We report the coefficients on the indicator variable denoting the younger sibling ("Younger"), the injury exposure index ("Injury index"), and the interaction of these two variables. The injury exposure index is the number of inpatient admissions with any injury (incl. poisoning) primary diagnosis among children aged 13-71 months per 100 children in each child's municipality of birth during the first year of life, excluding any hospitalizations of an older sibling. All specifications include municipality, year of birth, and month of birth fixed effects. Column (5) also includes the following family background controls: indicator for child gender, mother's age and age squared, indicator for the mother being foreign-born, indicators for mother's education level (high school degree, college degree or higher), and an indicator for the parents being married or cohabiting at the time of childbirth. Standard errors are clustered on the child's municipality of birth in all models. The "25th to 75th pctile effect size" row reports the magnitude of the differential effect of an increase in the disease exposure index from the 25th to the 75 th percentile of the distribution for younger siblings. Significance levels: ${ }^{*} \mathrm{p}<0.1{ }^{* *} \mathrm{p}<0.05 * * * \mathrm{p}<0.01$. 
Table A4: Effect of Respiratory Disease Exposure Index on Non-Infectious Digestive Disease Hospitalizations in First Year of Life, Younger versus Older Siblings

\begin{tabular}{lccccc}
\hline \hline & \multicolumn{3}{c}{ Non-infectious Digestive Disease Hospitalizations in First Year of Life $\left.*^{*} 1000\right)$} \\
\cline { 2 - 6 } & $(1)$ & $(2)$ & $(3)$ & $(4)$ & $(5)$ \\
\hline Younger & $-0.392^{* * *}$ & & $-0.393^{* * *}$ & 0.248 & 0.346 \\
& $(0.146)$ & & $(0.146)$ & $(0.390)$ & $(0.377)$ \\
Disease index & & -0.233 & -0.235 & -0.109 & -0.112 \\
& & $(0.156)$ & $(0.156)$ & $(0.146)$ & $(0.146)$ \\
Younger x disease index & & & & $-0.213^{*}$ & $-0.212^{*}$ \\
& & & & $(0.121)$ & $(0.121)$ \\
Municipality FEs & Yes & Yes & Yes & Yes & Yes \\
YoB+MoB FEs & Yes & Yes & Yes & Yes & Yes \\
Family Background Controls & No & No & No & No & 697,128 \\
Observations & 697,128 & 697,128 & 697,128 & 697,128 & 2.275 \\
Mean & 2.275 & 2.275 & 2.275 & 2.275 & -0.392 \\
25th to 75th pctile effect size & & & & -0.392 & \\
\hline \hline
\end{tabular}

Notes: Each column in each panel in the table presents results from estimating different versions of model (1). The outcome is the number of hospitalizations with any non-infectious digestive disease primary diagnosis during the first year of the child's life. We report the coefficients on the indicator variable denoting the younger sibling ("Younger"), the respiratory disease exposure index ("Disease index"), and the interaction of these two variables. The disease exposure index is the number of inpatient admissions with a respiratory disease primary diagnosis among children aged 13-71 months per 100 children in each child's municipality of birth during the first year of life, excluding any hospitalizations of an older sibling. All specifications include municipality, year of birth, and month of birth fixed effects. Column (5) also includes the following family background controls: indicator for child gender, mother's age and age squared, indicator for the mother being foreign-born, indicators for mother's education level (high school degree, college degree or higher), and an indicator for the parents being married or cohabiting at the time of childbirth. Standard errors are clustered on the child's municipality of birth in all models. The " 25 th to 75 th pctile effect size" row reports the magnitude of the differential effect of an increase in the disease exposure index from the 25th to the 75th percentile of the distribution for younger siblings. Significance levels: $* \mathrm{p}<0.1 * * \mathrm{p}<0.05 * * * \mathrm{p}<0.01$. 
Table A5: Effect of Respiratory Disease Exposure Index on Injury (incl. Poisoning) Hospitalizations in First Year of Life, Younger versus Older Siblings

\begin{tabular}{lccccc}
\hline \hline & \multicolumn{4}{l}{ Injury (incl. Poisonings) Hospitalizations in First Year of Life $\left(^{*} 1000\right)$} \\
\cline { 2 - 6 } & $(1)$ & $(2)$ & $(3)$ & $(4)$ & $(5)$ \\
\hline Younger & $-2.427^{* * *}$ & & $-2.415^{* * *}$ & 2.134 & $8.661^{* * *}$ \\
Disease index & $(0.842)$ & & $(0.840)$ & $(2.427)$ & $(2.799)$ \\
& & $2.341^{* * *}$ & $2.333^{* * *}$ & $3.228^{* * *}$ & $3.110^{* * *}$ \\
Younger x disease index & & $(0.663)$ & $(0.661)$ & $(0.909)$ & $(0.958)$ \\
& & & & $-1.509^{*}$ & -1.475 \\
Municipality FEs & & & & $(0.789)$ & $(0.896)$ \\
YoB+MoB FEs & Yes & Yes & Yes & Yes & Yes \\
Family Background Controls & Yes & Yes & Yes & Yes & Yes \\
\hline Observations & 697,128 & 697,128 & 697,128 & 697,128 & Nos \\
Mean & 50.965 & 50.965 & 50.965 & 50.965 & 697,128 \\
25th to 75th pctile effect size & & & & -2.783 & -2.720 \\
\hline \hline
\end{tabular}

Notes: Each column in each panel in the table presents results from estimating different versions of model (1), with an index based on injury (incl. poisoning) hospitalizations instead of respiratory disease hospitalizations. The outcome is the number of hospitalizations with any injury (incl. poisoning) primary diagnosis during the first year of the child's life. We report the coefficients on the indicator variable denoting the younger sibling ("Younger"), the respiratory disease exposure index ("Disease index"), and the interaction of these two variables. The disease exposure index is the number of inpatient admissions with a respiratory disease primary diagnosis among children aged 13-71 months per 100 children in each child's municipality of birth during the first year of life, excluding any hospitalizations of an older sibling. All specifications include municipality, year of birth, and month of birth fixed effects. Column (5) also includes the following family background controls: indicator for child gender, mother's age and age squared, indicator for the mother being foreign-born, indicators for mother's education level (high school degree, college degree or higher), and an indicator for the parents being married or cohabiting at the time of childbirth. Standard errors are clustered on the child's municipality of birth in all models. The "25th to 75th pctile effect size" row reports the magnitude of the differential effect of an increase in the disease exposure index from the 25th to the 75 th percentile of the distribution for younger siblings. Significance levels: ${ }^{*} \mathrm{p}<0.1{ }^{* *} \mathrm{p}<0.05 * * * \mathrm{p}<0.01$. 
Table A6: Effect of Respiratory Disease Exposure Index in First Year of Life on 9th Grade Danish Test Score, Younger versus Older Siblings

\begin{tabular}{lcccc}
\hline \hline & \multicolumn{3}{c}{9 th Grade Danish Test Score } \\
\cline { 2 - 5 } & $(1)$ & $(2)$ & $(3)$ & $(4)$ \\
\hline Younger & $-0.190^{* * *}$ & & $-0.190^{* * *}$ & $-0.164^{* * *}$ \\
Disease index & $(0.006)$ & & $(0.006)$ & $(0.015)$ \\
& & -0.002 & -0.002 & 0.003 \\
Younger x disease index & & $(0.004)$ & $(0.004)$ & $(0.005)$ \\
& & & & $-0.009^{*}$ \\
Municipality FEs & Yes & Yes & Yes & $(0.005)$ \\
YoB+MoB FEs & Yes & Yes & Yes & Yes \\
Family Background Controls & Yes & Yes & Yes & Yes \\
\hline Observations & 474,184 & 474,184 & 474,184 & 474,184 \\
Mean & 0.100 & 0.100 & 0.100 & 0.100 \\
25th to 75th pctile effect size & & & & -0.016 \\
\hline \hline
\end{tabular}

Notes: See notes under Table 2 for more details about the specifications and variables. The outcome is the 9th grade Danish test score, which is converted into a $z$-score, standardized within each subject and test year. Test score data are only available for children born in 1986-2003. Standard errors are clustered on the child's municipality of birth. Significance levels: ${ }^{*} \mathrm{p}<0.1{ }^{* *} \mathrm{p}<0.05^{* * *} \mathrm{p}<0.01$. 
Table A7: Effect of Respiratory Disease Exposure Index in First Year of Life on 9th Grade Math Test Score, Younger versus Older Siblings

\begin{tabular}{lcccc}
\hline \hline & \multicolumn{3}{c}{ 9th Grade Math Test Score } \\
\cline { 2 - 5 } & $(1)$ & $(2)$ & $(3)$ & $(4)$ \\
\hline Younger & $-0.239^{* * *}$ & & $-0.239^{* * *}$ & $-0.219^{* * *}$ \\
& $(0.010)$ & & $(0.010)$ & $(0.013)$ \\
Disease index & & -0.001 & -0.001 & 0.003 \\
& & $(0.004)$ & $(0.004)$ & $(0.004)$ \\
Younger x disease index & & & & -0.007 \\
& & & & $(0.005)$ \\
Municipality FEs & Yes & Yes & Yes & Yes \\
YoB+MoB FEs & Yes & Yes & Yes & Yes \\
Family Background Controls & Yes & Yes & Yes & Yes \\
\hline Observations & 475,944 & 475,944 & 475,944 & 475,944 \\
Mean & 0.142 & 0.142 & 0.142 & 0.142 \\
25th to 75th pctile effect size & & & & -0.012 \\
\hline \hline
\end{tabular}

Notes: See notes under Table 2 for more details about the specifications and variables. The outcome is the 9th grade math test score, which is converted into a $z$-score, standardized within each subject and test year. Test score data are only available for children born in 1986-2003. Standard errors are clustered on the child's municipality of birth. Significance levels: ${ }^{*} \mathrm{p}<0.1{ }^{* *} \mathrm{p}<0.05^{* * *} \mathrm{p}<0.01$. 
Table A8: Robustness of Results on Respiratory Disease Hospitalizations in First Year of Life

\begin{tabular}{|c|c|c|c|c|c|c|}
\hline & 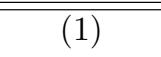 & 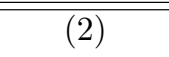 & $(3)$ & $(4)$ & $(5)$ & $(6)$ \\
\hline \multicolumn{7}{|c|}{ A. Respiratory Disease Hospitalizations in First Year of Life } \\
\hline Younger & $\begin{array}{c}0.017^{* * *} \\
(0.002)\end{array}$ & $\begin{array}{c}0.006^{* * *} \\
(0.002)\end{array}$ & $\begin{array}{c}0.016^{* * *} \\
(0.002)\end{array}$ & $\begin{array}{c}0.036^{* * *} \\
(0.005)\end{array}$ & $\begin{array}{c}0.015^{* * *} \\
(0.002)\end{array}$ & $\begin{array}{c}0.017^{* * *} \\
(0.002)\end{array}$ \\
\hline Disease index & $\begin{array}{c}0.010^{* * *} \\
(0.001)\end{array}$ & $\begin{array}{c}0.010^{* * *} \\
(0.001)\end{array}$ & $\begin{array}{c}0.007^{* * *} \\
(0.001)\end{array}$ & $\begin{array}{c}0.004^{* * *} \\
(0.002)\end{array}$ & & \\
\hline Younger $\mathrm{x}$ disease index & $\begin{array}{c}0.012^{* * *} \\
(0.001)\end{array}$ & $\begin{array}{c}0.011^{* * *} \\
(0.001)\end{array}$ & $\begin{array}{c}0.012^{* * *} \\
(0.001)\end{array}$ & $\begin{array}{c}0.013^{* * *} \\
(0.001)\end{array}$ & & \\
\hline Disease index (\# Diagnosis) & & & & & $\begin{array}{c}0.005^{* * *} \\
(0.001)\end{array}$ & \\
\hline Younger x disease index (\# Diagnosis) & & & & & $\begin{array}{c}0.008^{* * *} \\
(0.000)\end{array}$ & \\
\hline Disease index (\# Kids) & & & & & & $\begin{array}{c}0.011^{* * *} \\
(0.001)\end{array}$ \\
\hline Younger x disease index (\# Kids) & & & & & & $\begin{array}{c}0.013^{* * *} \\
(0.001)\end{array}$ \\
\hline Observations & $1,176,746$ & $1,176,746$ & $1,176,746$ & $1,176,746$ & $1,176,746$ & $1,176,746$ \\
\hline Mean & 0.068 & 0.068 & 0.068 & 0.068 & 0.068 & 0.068 \\
\hline 25 th to 75 th pctile effect size & 0.021 & 0.021 & 0.022 & 0.024 & 0.021 & 0.021 \\
\hline \multicolumn{7}{|c|}{ B. RSV Hospitalizations in First Year of Life } \\
\hline Younger & $\begin{array}{c}0.016^{* * *} \\
(0.001)\end{array}$ & $\begin{array}{c}0.013^{* * *} \\
(0.001)\end{array}$ & $\begin{array}{c}0.016^{* * *} \\
(0.001)\end{array}$ & $\begin{array}{c}0.028^{* * *} \\
(0.002)\end{array}$ & $\begin{array}{c}0.016^{* * *} \\
(0.001)\end{array}$ & $\begin{array}{c}0.016^{* * *} \\
(0.001)\end{array}$ \\
\hline Disease index & $\begin{array}{c}0.016^{* * *} \\
(0.003)\end{array}$ & $\begin{array}{c}0.016^{* * *} \\
(0.003)\end{array}$ & $\begin{array}{c}0.011^{* * *} \\
(0.003)\end{array}$ & $\begin{array}{c}0.004 \\
(0.006)\end{array}$ & & \\
\hline Younger $\mathrm{x}$ disease index & $\begin{array}{c}0.046^{* * *} \\
(0.004)\end{array}$ & $\begin{array}{c}0.046^{* * *} \\
(0.004)\end{array}$ & $\begin{array}{c}0.043^{* * *} \\
(0.004)\end{array}$ & $\begin{array}{c}0.048^{* * *} \\
(0.007)\end{array}$ & & \\
\hline Disease index (\# Diagnosis) & & & & & $\begin{array}{c}0.012^{* * *} \\
(0.002)\end{array}$ & \\
\hline Younger x disease index (\# Diagnosis) & & & & & $\begin{array}{c}0.034^{* * *} \\
(0.004)\end{array}$ & \\
\hline Disease index (\# Kids) & & & & & & $\begin{array}{c}0.017^{* * *} \\
(0.003)\end{array}$ \\
\hline Younger $\mathrm{x}$ disease index (\# Kids) & & & & & & $\begin{array}{c}0.049^{* * *} \\
(0.004)\end{array}$ \\
\hline Observations & 697,128 & 697,128 & 697,128 & 697,128 & 697,128 & 697,128 \\
\hline Mean & 0.018 & 0.018 & 0.018 & 0.018 & 0.018 & 0.018 \\
\hline 25 th to 75 th pctile effect size & 0.005 & 0.005 & 0.005 & 0.005 & 0.005 & 0.005 \\
\hline Municipality FEs & Yes & Yes & Yes & Yes & Yes & Yes \\
\hline YoB+MoB FEs & Yes & Yes & Yes & Yes & Yes & Yes \\
\hline Family Background Controls & Yes & No & Yes & Yes & Yes & Yes \\
\hline Mother FEs & No & No & No & Yes & No & No \\
\hline Municipality Trends & No & No & Yes & No & No & No \\
\hline
\end{tabular}

Notes: Each column in the table presents results from estimating different versions of model (1). The outcome is the number of hospitalizations with a respiratory disease primary diagnosis (Panel A) or with a RSV primary diagnosis (Panel B) during the first year of the child's life. Column (1) presents results using baseline model. Column (2) drops family background controls. Column (3) adds municipality-specific linear time trends and Column (4) adds maternal fixed effects. Column (5) uses a disease index in which we count number of diagnoses for respiratory conditions in hospitalizations including both primary and non-primary diagnoses. Column (6) uses a disease index in which we calculate the number of children with at least one respiratory disease diagnosis (i.e., counting the number of children and not the total number of diagnoses). See notes under Table 2 for more details about our baseline model and control variables. Standard errors are clustered on the child's municipality of birth in all models. The "25th to 75th pctile effect size" row reports the magnitude of the differential effect of an increase in the disease exposurq $\dot{0}$ dex from the 25 th to the 75 th percentile of the distribution for younger siblings. Significance levels: $* \mathrm{p}<0.1 * * \mathrm{p}<0.05 * * * \mathrm{p}<0.01$. 
Table A9: Robustness of Results on High School Graduation by Age 30

\begin{tabular}{|c|c|c|c|c|c|c|}
\hline & \multicolumn{6}{|c|}{ "Graduated High School by Age 30} \\
\hline & $(1)$ & $(2)$ & $(3)$ & (4) & $(5)$ & $(6)$ \\
\hline Younger & $\begin{array}{c}-0.044^{* * *} \\
(0.004)\end{array}$ & $\begin{array}{c}0.000 \\
(0.004)\end{array}$ & $\begin{array}{c}-0.048^{* * *} \\
(0.005)\end{array}$ & $\begin{array}{l}-0.008 \\
(0.008)\end{array}$ & $\begin{array}{c}-0.043^{* * *} \\
(0.004)\end{array}$ & $\begin{array}{c}-0.044^{* * *} \\
(0.004)\end{array}$ \\
\hline Disease index & $\begin{array}{l}0.006^{* *} \\
(0.003)\end{array}$ & $\begin{array}{l}0.007^{* *} \\
(0.003)\end{array}$ & $\begin{array}{l}0.005^{*} \\
(0.003)\end{array}$ & $\begin{array}{l}0.009^{*} \\
(0.005)\end{array}$ & & \\
\hline Younger $\mathrm{x}$ disease index & $\begin{array}{r}-0.003^{* *} \\
(0.001)\end{array}$ & $\begin{array}{l}-0.003 \\
(0.002)\end{array}$ & $\begin{array}{l}-0.001 \\
(0.002)\end{array}$ & $\begin{array}{l}-0.004 \\
(0.003)\end{array}$ & & \\
\hline Disease index (\# Diagnosis) & & & & & $\begin{array}{c}0.005^{* * *} \\
(0.002)\end{array}$ & \\
\hline Younger x disease index (\# Diagnosis) & & & & & $\begin{array}{c}-0.002^{* * *} \\
(0.001)\end{array}$ & \\
\hline Disease index (\# Kids) & & & & & & $\begin{array}{l}0.006^{*} \\
(0.003)\end{array}$ \\
\hline Younger $\mathrm{x}$ disease index (\# Kids) & & & & & & $\begin{array}{c}-0.003^{* *} \\
(0.002)\end{array}$ \\
\hline Municipality FEs & Yes & Yes & Yes & Yes & Yes & Yes \\
\hline YoB+MoB FEs & Yes & Yes & Yes & Yes & Yes & Yes \\
\hline Family Background Controls & Yes & No & Yes & Yes & Yes & Yes \\
\hline Mother FEs & No & No & No & Yes & No & No \\
\hline Municipality Trends & No & No & Yes & No & No & No \\
\hline Observations & 148,876 & 148,876 & 148,876 & 148,876 & 148,876 & 148,876 \\
\hline Mean & 0.844 & 0.844 & 0.844 & 0.844 & 0.844 & 0.844 \\
\hline 25 th to 75 th pctile effect size & -0.004 & -0.004 & -0.001 & -0.005 & -0.004 & -0.004 \\
\hline
\end{tabular}

Notes: See notes under Appendix Table A8 for more details about the specifications and variables. The outcome is an indicator for graduating high school by age 30 . Standard errors are clustered on the child's municipality of birth. Significance levels: ${ }^{*} \mathrm{p}<0.1 * * \mathrm{p}<0.05 * * * \mathrm{p}<0.01$. 
Table A10: Robustness of Results on College Graduation by Age 30

\begin{tabular}{|c|c|c|c|c|c|c|}
\hline & \multicolumn{6}{|c|}{ Graduated College by Age 30} \\
\hline & (1) & $(2)$ & (3) & $(4)$ & $(5)$ & $(6)$ \\
\hline Younger & $\begin{array}{c}-0.082^{* * *} \\
(0.006)\end{array}$ & $\begin{array}{c}-0.014^{*} \\
(0.007)\end{array}$ & $\begin{array}{c}-0.081^{* * *} \\
(0.008)\end{array}$ & $\begin{array}{c}-0.038^{* * *} \\
(0.011)\end{array}$ & $\begin{array}{c}-0.082^{* * *} \\
(0.006)\end{array}$ & $\begin{array}{c}-0.082^{* * *} \\
(0.006)\end{array}$ \\
\hline Disease index & $\begin{array}{c}0.002 \\
(0.003)\end{array}$ & $\begin{array}{c}0.003 \\
(0.003)\end{array}$ & $\begin{array}{c}0.003 \\
(0.003)\end{array}$ & $\begin{array}{c}0.005 \\
(0.005)\end{array}$ & & \\
\hline Younger $\mathrm{x}$ disease index & $\begin{array}{l}-0.003 \\
(0.002)\end{array}$ & $\begin{array}{l}-0.002 \\
(0.004)\end{array}$ & $\begin{array}{l}-0.004 \\
(0.003)\end{array}$ & $\begin{array}{l}-0.003 \\
(0.003)\end{array}$ & & \\
\hline Disease index (\# Diagnosis) & & & & & $\begin{array}{c}0.003 \\
(0.002)\end{array}$ & \\
\hline Younger x disease index (\# Diagnosis) & & & & & $\begin{array}{l}-0.003^{*} \\
(0.002)\end{array}$ & \\
\hline Disease index (\# Kids) & & & & & & $\begin{array}{c}0.001 \\
(0.003)\end{array}$ \\
\hline Younger $\mathrm{x}$ disease index (\# Kids) & & & & & & $\begin{array}{l}-0.004 \\
(0.002)\end{array}$ \\
\hline Municipality FEs & Yes & Yes & Yes & Yes & Yes & Yes \\
\hline $\mathrm{YoB}+\mathrm{MoB}$ FEs & Yes & Yes & Yes & Yes & Yes & Yes \\
\hline Family Background Controls & Yes & No & Yes & Yes & Yes & Yes \\
\hline Mother FEs & No & No & No & Yes & No & No \\
\hline Municipality Trends & No & No & Yes & No & No & No \\
\hline Observations & 148,876 & 148,876 & 148,876 & 148,876 & 148,876 & 148,876 \\
\hline Mean & 0.437 & 0.437 & 0.437 & 0.437 & 0.437 & 0.437 \\
\hline 25 th to 75 th pctile effect size & -0.004 & -0.003 & -0.005 & -0.003 & -0.004 & -0.004 \\
\hline
\end{tabular}

Notes: See notes under Appendix Table A8 for more details about the specifications and variables. The outcome is an indicator for graduating college by age 30. Standard errors are clustered on the child's municipality of birth. Significance levels: ${ }^{*} \mathrm{p}<0.1 * * \mathrm{p}<0.05 * * * \mathrm{p}<0.01$. 
Table A11: Robustness of Results on Labor Force Participation at Age 30

\begin{tabular}{|c|c|c|c|c|c|c|}
\hline & \multicolumn{6}{|c|}{ Labor Force Participation at Age 30} \\
\hline & (1) & (2) & (3) & $(4)$ & $(5)$ & (6) \\
\hline Younger & $\begin{array}{c}-0.016^{* * *} \\
(0.006)\end{array}$ & $\begin{array}{l}-0.000 \\
(0.005)\end{array}$ & $\begin{array}{c}-0.022^{* * *} \\
(0.006)\end{array}$ & $\begin{array}{c}0.001 \\
(0.009)\end{array}$ & $\begin{array}{c}-0.015^{* * *} \\
(0.005)\end{array}$ & $\begin{array}{c}-0.016^{* * *} \\
(0.006)\end{array}$ \\
\hline Disease index & $\begin{array}{c}0.000 \\
(0.003)\end{array}$ & $\begin{array}{c}0.001 \\
(0.003)\end{array}$ & $\begin{array}{l}-0.000 \\
(0.003)\end{array}$ & $\begin{array}{c}0.006 \\
(0.005)\end{array}$ & & \\
\hline Younger $\mathrm{x}$ disease index & $\begin{array}{l}-0.001 \\
(0.002)\end{array}$ & $\begin{array}{l}-0.002 \\
(0.002)\end{array}$ & $\begin{array}{c}0.002 \\
(0.002)\end{array}$ & $\begin{array}{l}-0.004 \\
(0.002)\end{array}$ & & \\
\hline Disease index (\# Diagnosis) & & & & & $\begin{array}{c}0.001 \\
(0.002)\end{array}$ & \\
\hline Younger x disease index (\# Diagnosis) & & & & & $\begin{array}{l}-0.001 \\
(0.001)\end{array}$ & \\
\hline Disease index (\# Kids) & & & & & & $\begin{array}{l}-0.000 \\
(0.003)\end{array}$ \\
\hline Younger $\mathrm{x}$ disease index (\# Kids) & & & & & & $\begin{array}{l}-0.001 \\
(0.002)\end{array}$ \\
\hline Municipality FEs & Yes & Yes & Yes & Yes & Yes & Yes \\
\hline YoB+MoB FEs & Yes & Yes & Yes & Yes & Yes & Yes \\
\hline Family Background Controls & Yes & No & Yes & Yes & Yes & Yes \\
\hline Mother FEs & No & No & No & Yes & No & No \\
\hline Municipality Trends & No & No & Yes & No & No & No \\
\hline Observations & 165,736 & 165,736 & 165,736 & 165,736 & 165,736 & 165,736 \\
\hline Mean & 0.802 & 0.802 & 0.802 & 0.802 & 0.802 & 0.802 \\
\hline 25 th to 75 th pctile effect size & -0.001 & -0.002 & 0.002 & -0.005 & -0.002 & -0.001 \\
\hline
\end{tabular}

Notes: See notes under Appendix Table A8 for more details about the specifications and variables. The outcome is an indicator for being employed at age 30. Standard errors are clustered on the child's municipality of birth. Significance levels: ${ }^{*} \mathrm{p}<0.1{ }^{* *} \mathrm{p}<0.05^{* * *} \mathrm{p}<0.01$. 
Table A12: Robustness of Results on Log Income (Conditional on Employed) at Age 30

\begin{tabular}{|c|c|c|c|c|c|c|}
\hline & \multicolumn{6}{|c|}{ Log Income at Age 30} \\
\hline & (1) & (2) & (3) & (4) & (5) & (6) \\
\hline Younger & $\begin{array}{l}-0.005 \\
(0.005)\end{array}$ & $\begin{array}{c}0.005 \\
(0.005)\end{array}$ & $\begin{array}{l}-0.010 \\
(0.006)\end{array}$ & $\begin{array}{c}0.005 \\
(0.009)\end{array}$ & $\begin{array}{l}-0.006 \\
(0.005)\end{array}$ & $\begin{array}{l}-0.005 \\
(0.005)\end{array}$ \\
\hline Disease index & $\begin{array}{c}0.002 \\
(0.003)\end{array}$ & $\begin{array}{c}0.001 \\
(0.003)\end{array}$ & $\begin{array}{l}-0.000 \\
(0.004)\end{array}$ & $\begin{array}{c}0.002 \\
(0.006)\end{array}$ & & \\
\hline Younger $\mathrm{x}$ disease index & $\begin{array}{c}-0.011^{* * *} \\
(0.002)\end{array}$ & $\begin{array}{c}-0.010^{* * *} \\
(0.002)\end{array}$ & $\begin{array}{c}-0.009^{* * *} \\
(0.003)\end{array}$ & $\begin{array}{c}-0.008^{* *} \\
(0.004)\end{array}$ & & \\
\hline Disease index (\# Diagnosis) & & & & & $\begin{array}{c}0.001 \\
(0.002)\end{array}$ & \\
\hline Younger x disease index (\# Diagnosis) & & & & & $\begin{array}{c}-0.007^{* * *} \\
(0.001)\end{array}$ & \\
\hline Disease index (\# Kids) & & & & & & $\begin{array}{c}0.002 \\
(0.003)\end{array}$ \\
\hline Younger x disease index (\# Kids) & & & & & & $\begin{array}{r}-0.011^{* * *} \\
(0.002)\end{array}$ \\
\hline Municipality FEs & Yes & Yes & Yes & Yes & Yes & Yes \\
\hline YoB + MoB FEs & Yes & Yes & Yes & Yes & Yes & Yes \\
\hline Family Background Controls & Yes & No & Yes & Yes & Yes & Yes \\
\hline Mother FEs & No & No & No & Yes & No & No \\
\hline Municipality Trends & No & No & Yes & No & No & No \\
\hline Observations & 104,806 & 104,806 & 104,806 & 104,806 & 104,806 & 104,806 \\
\hline Mean & 11.019 & 11.019 & 11.019 & 11.019 & 11.019 & 11.019 \\
\hline 25 th to 75 th pctile effect size & -0.013 & -0.012 & -0.010 & -0.009 & -0.012 & -0.013 \\
\hline
\end{tabular}

Notes: See notes under Appendix Table A8 for more details about the specifications and variables. The outcome is the log of gross personal income (conditional on employed) at age 30. Standard errors are clustered on the child's municipality of birth. Significance levels: ${ }^{*} \mathrm{p}<0.1{ }^{* *} \mathrm{p}<0.05^{* * *} \mathrm{p}<0.01$. 